\title{
THE MOST IMPORTANT ECONOMIC INDICATORS OF CONSUMPTION EXPENDITURE OF VEGETABLES IN RURAL AND URBAN EGYPT
}

\author{
TAHER M. SAIED KADAH
}

Agricultural Economics Research Institute, ARC, Dokki, Giza.

(Manuscript received 13 August 2018)

\begin{abstract}
$\mathrm{T}$ he research aims to prove the economic hypothesis that is provided by the economic theory by determining the positive relationship between the consumed quantities of vegetables and the average consumer income and the inverse relation between the quantity consumed and commodity prices.

The most important results of the study:

- The high level of demand for vegetables in rural area from urban according to the size of the family, Where the average annual individual expenditure on vegetables out of total expenditure on food and drink reached $7.4 \%, 6.8 \%$ in 2010/2011, 2015 in rural areas respectively, And about $6.5 \%, 5.4 \%$ in urban areas during the same two years.

- The Lorenz curve of the distribution of consumer spending on vegetables for urban and urban rural areas in Egypt indicates that urban consumption is more equitable in rural consumption because it is closer to the equality line. When we explain which categories are more fair, $50 \%$ of the higher income groups in urban areas are characterized by a fair distribution of consumption of vegetables, while $30 \%$ of the rural population of the lowest income groups are characterized by a fair distribution of consumption of vegetables.
\end{abstract}

\section{RECOMMENDATIONS}

- Not to fully raise government support and channel support to the poorest.

- Improving the standard of living of consumers as the government completes the process of economic reform to avoid the occurrence of crises that may arise as a result of increasing inflation.

- Conducting more sluotion about family budget research to monitor and evaluate changes in consumption patterns and living standards of different social strata in different regions and at different time periods.

- On the other side to provide annual data for consumer spending to conduct studies and research on consumption patterns to help the decision-maker better. 


\title{
أهم المؤشرات الإقتصادية للإنفاق الإستهلاكى للخضر فى ريف وحضر مصر
}

\section{طاهر محمد سعيد قدح}

$$
\text { معهة بحوث الاقتصاد الزراعي - مركز البحوث الزراعية - الدقي - الجيزة. }
$$

\begin{abstract}
مقدمة
يعد الإنفاق الإنتهلاكي وتوزيعه أحد أهم المؤشرات للتعرف على نمط توزيع الدخل

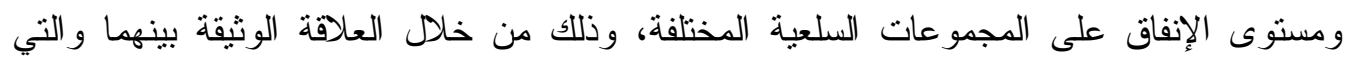

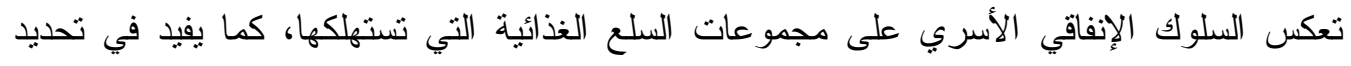

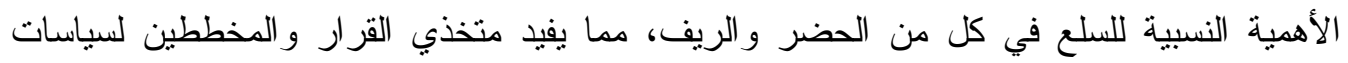
الإنتاج والإنتهلاك من خلا المؤشرات و النتائج في وضع الأسس الكفيلة بتحسين الدخول، وكذا

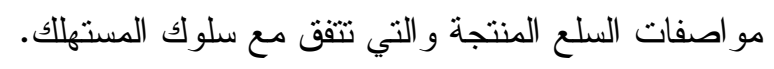

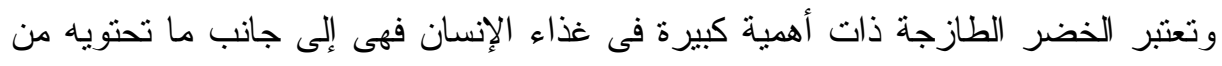

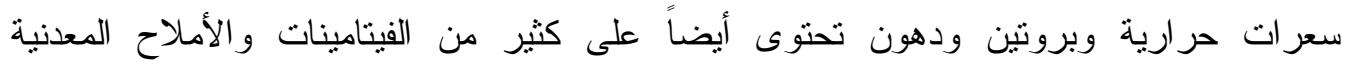

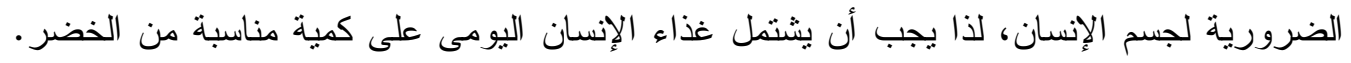

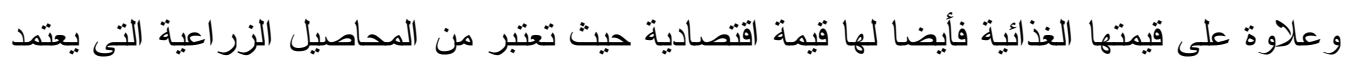
عليها الإقتصاد المصرى لزيادة الدخل القومي من العطلة الصعبة. وقد بلغ الإنتاج المحلى لفئل لمحاصيل

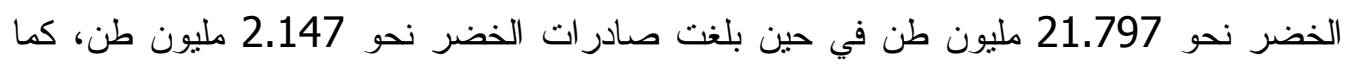

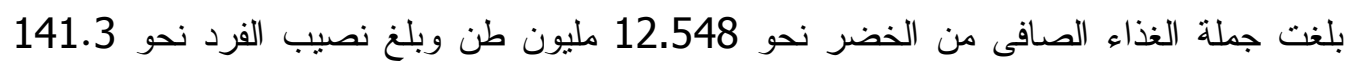
كيلو جرام فى السنة وذلك لعام 2015 (1). ولذلك تعتبر دراسات نوجيه وتخطيط الأستهلاك من أهم أهداف السياسة فى الوقت الحالى،

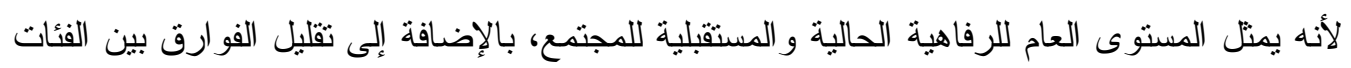
و الطبقات المختلفة فى كل من الريف و الحضر . لأل

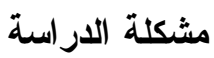

تأثر القطاع الزراعى فى الفترة الأخيرة ببعض المتغيرات الاقتصادية والتي أثزت بصورة

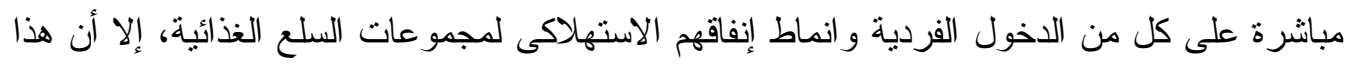

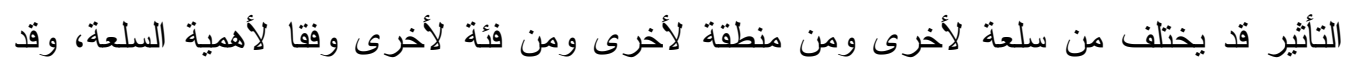
انعكست هذه التغيرات على جمهور المستهلكين وتغيرت بالتبعية أنماطهم الاستهلاكية وقد أدى ذلاثك 
إلى زيادة الإنفاق الاستهلاكى للفرد، ولذلك تمنلت مشكلة الدراسة حول التغيرات فى الإنفاق

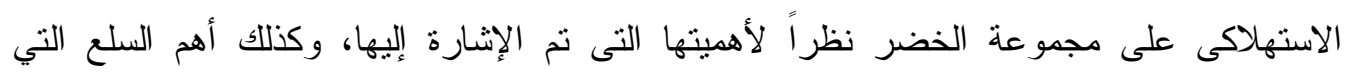

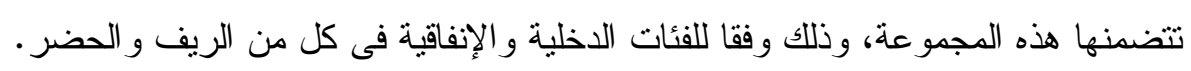

\section{هذف الدراسة}

يهدف البحث إلى إثبات الفرضية الاقتصادية النى تتص عليها النظرية الاقتصادية بتحديد العلاقة الطردية بين الكميات المستهكة من الخضر ومنوسط دخل المستهلك و العلاقة العكسية بين الكمية المستهلكة وأسعار السلع. و ذلك من خلال ما يلى الطئ

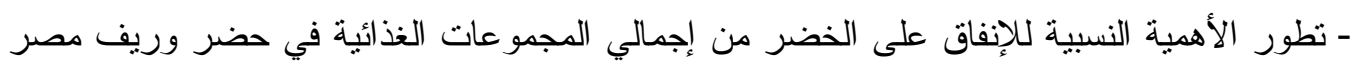
و إجمالي الجمهورية خلال الفترة 2000/1999-2015.

- تقدير الدوال الإنفاقية للخضر وفقا لبيانات بحث الدخل والإنفاق والاستهلاك خلد الفترة 2015-2011/2010

- تقدير المرونات الدخلية الإنفاقية لأهم سلع الخضر للفئات الإنفاقية المختلفة وفقا لبحث الدخل و الإنفاق و الاستهلاك فيما بين عامي (2015/2010-2011).

- قياس ددى نأثثر بعض العوامل الإجتماعية على الإنفاق لإجمالي الخضر في كل من الحضر و الريف خلال الفترة (2011/2010 - 2015).

- قياس منحنى لورنز لقياس توزيع الدخل (الإنفاق) لمجموعة الخضر فى ريف وحضر مصر .

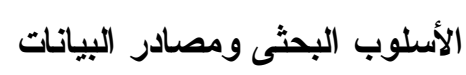

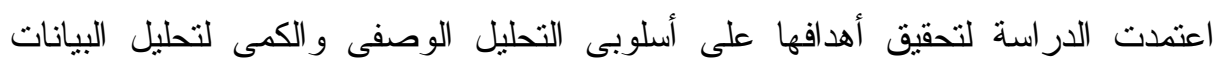
وتفسير النتائج، حيث تم استخدام بعض الأدوات الإحصائية البسيطة متل المتوسطات الحسابية ومعدلات التغير. كما تم تطبيق بعض النماذج القياسية بصور رياضية متعددة لقياس العلاقات الإستهلاكية الإنفاقية وتقدير المرونات بأنو اعها.

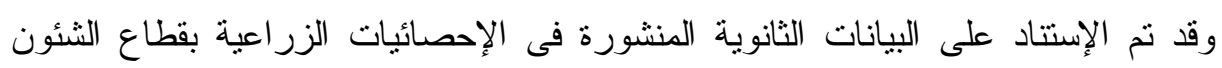

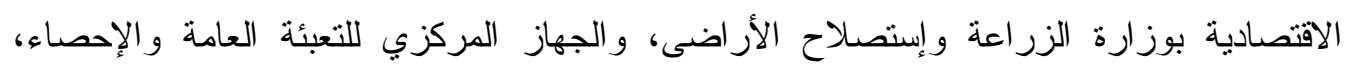

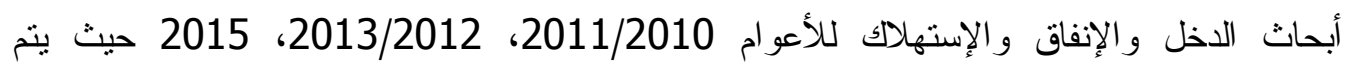
الإعتماد عليها فى هذا المجال لأنها نتفر العديد من المؤشر ات الإقتصادية والإجتماعية و الديموجر افية الإنة

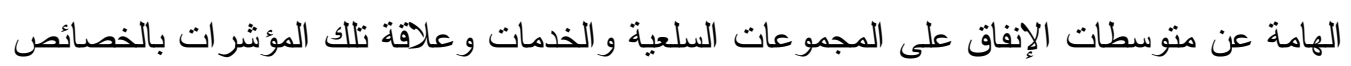

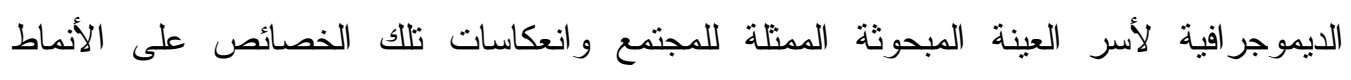

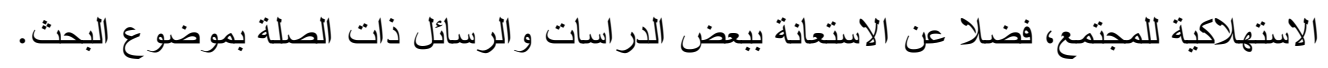

\section{الإطار المرجعي}

أوضح عمارة وآخرون(1) عام 2017 أن المرونة الإنفاقية للخضر بعينة الدراسة (منطقة الجبل 0.77 المبل 0.96 ،

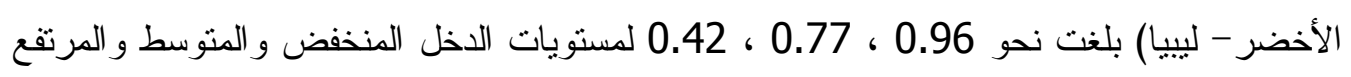


على الترتيب وهى موجبة وأقل من الو احد الصحيح مما يدل على أن الزيادة النسبية فى الدخل تؤدى إلى إلى

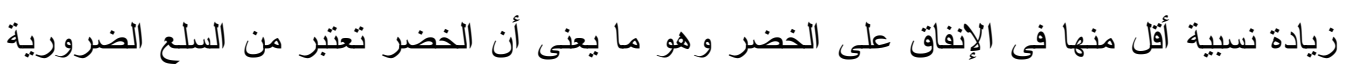
لمختلف الفئات الدخلية الإنفاقية. وبين محمود (2) عام 2017 أن المرونة الإنقاقية للخضر بلغت حو الى (0.53 ، 0.48) لكل من

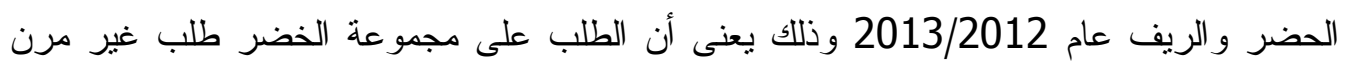
وبالتالي تعتبر مجمو عة الخضر من السلع الضرورية. كما نوصلت دراسة هنادى وأزهرية (3)عام 2016 إلى أنه كلما زاد حجم الأسرة زاد الناد

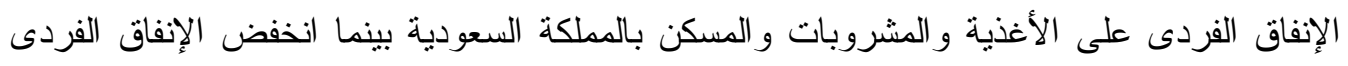

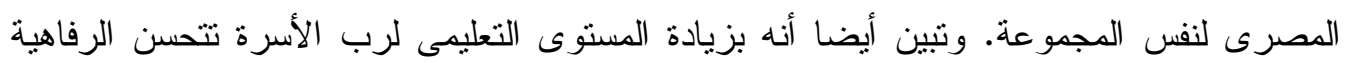

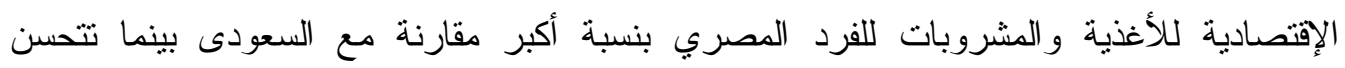

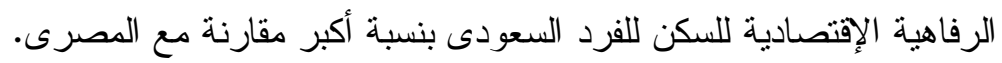

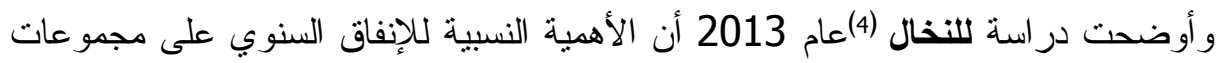

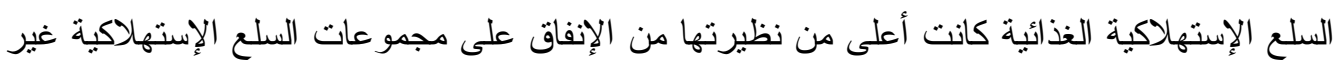

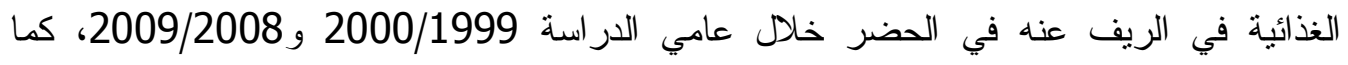

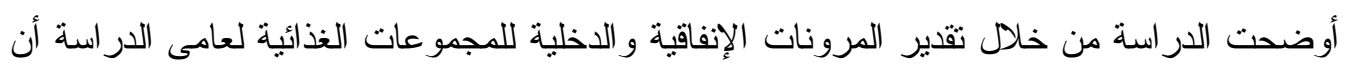

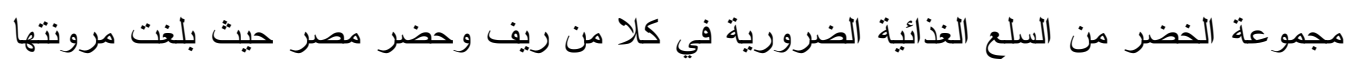

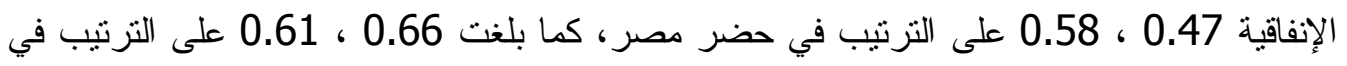

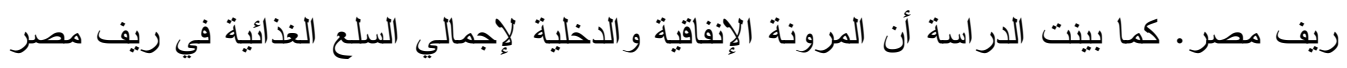

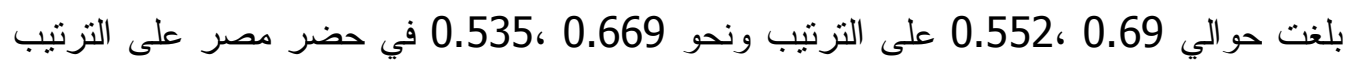

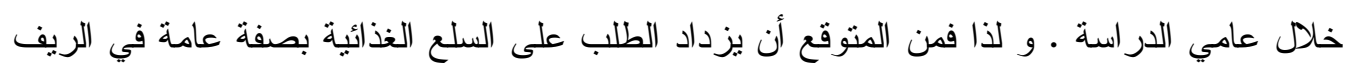

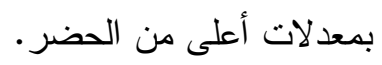

\section{نتائج الار اسة}

1. تطور الأهمية النسبية للإنفاق على الخضر من إجمالي المجموعات الغذائية في حضر وريف

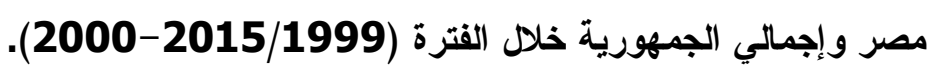

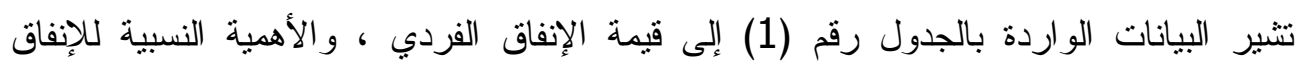

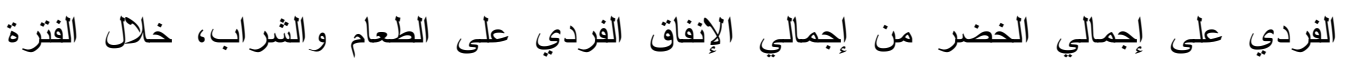
(2015-2000/1999)، ومن الجدول يتبين ما يلي:

(2) حسن يوسف محمود ، در اسة اقتصادية لأنماط الاستهلاك الغذائى بمحافظ أسيوط، المجلة المصريةل للاقتصاد الزر اعي ،

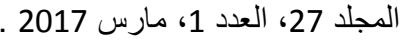

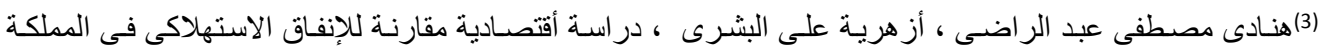

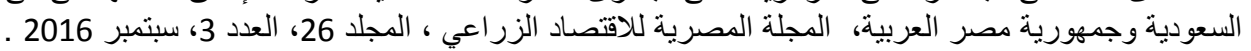
(4)جمال عبدالحميد عبدالحميد نخال، دراسة تحليلية للإنفاق الاستهلاكي لريف و حضر مصر، المجلة المصرية للاقتصاد الزراعي، المجلد (23)، العدد(1)، مارس 2013. 


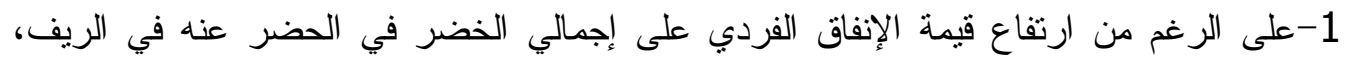

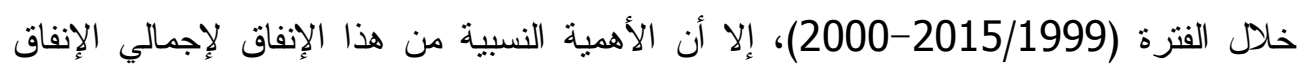

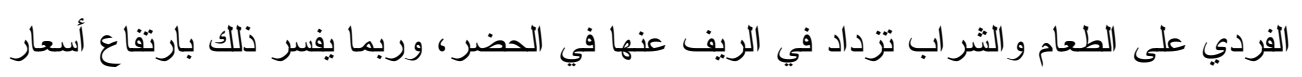

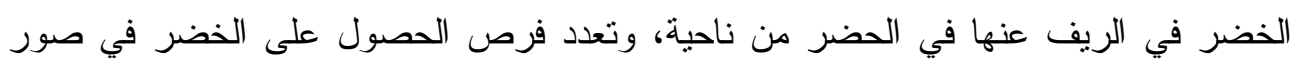

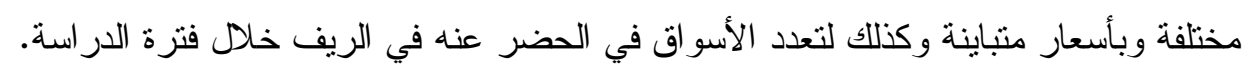

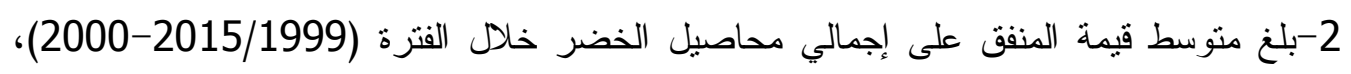

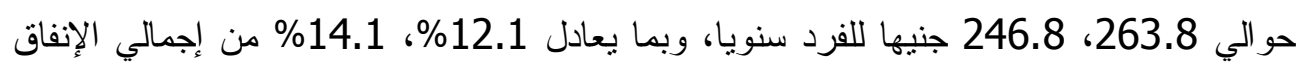
الفردي على الطعام و الثر اب في كل من الحضر و الريف على الترتيب.

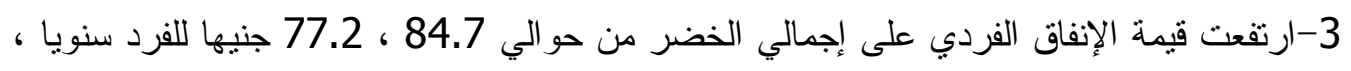
وبما يعادل نحو 9.5\%، 10.8\% من إجمالي الإنفاق الفردي على الطعام و الثراب وذللك لكلا

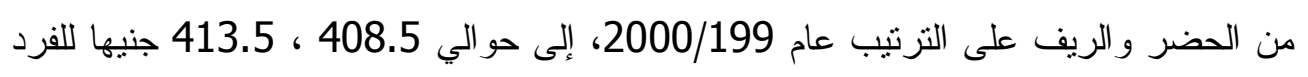

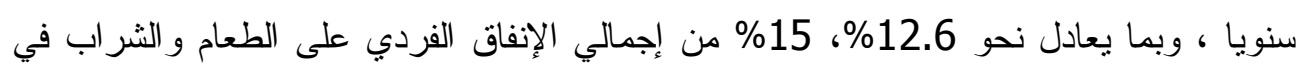

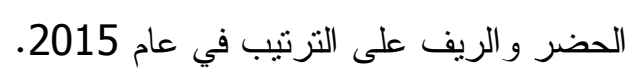

جدول (1): نطور القيمة والأهمية النسبية للإنفاق الفردي على إجمالي الخضر من إجمالي الإنفاق على الطعام و الثر اب في حضر وريف مصر خلال الفترة (2015/1999-2000).

\begin{tabular}{|c|c|c|c|c|c|c|}
\hline \multirow{2}{*}{\multicolumn{2}{|c|}{ إجمالي الإنفاق على الطعام والثر اب }} & \multicolumn{4}{|c|}{ الخضر } & \multirow{3}{*}{ لبيان } \\
\hline & & \multicolumn{2}{|c|}{ ريف } & \multicolumn{2}{|c|}{ حضر } & \\
\hline ريف & حضر & $(\%)$ & جنيه & $(\%)$ & جنيه & \\
\hline 714.4 & 891.8 & 10.8 & 77.2 & 9.5 & 84.7 & $2000 / 1999$ \\
\hline 975.6 & 1347 & 13.6 & 132.4 & 11.1 & 149 & $2005 / 2004$ \\
\hline 1795.2 & 2311.1 & 16.2 & 290.5 & 14.3 & 331.3 & $2011 / 2010$ \\
\hline 2066 & 2563.3 & 15.5 & 320.3 & 13.5 & 345.3 & $2013 / 2012$ \\
\hline 2760.6 & 3229.8 & 15.0 & 413.5 & 12.6 & 408.5 & 2015 \\
\hline 1662.4 & 2068.6 & 14.1 & 246.8 & 12.1 & 263.8 & المتوسط ("*) \\
\hline
\end{tabular}

(") المتوسط الحسابي للقيمة و المتوسط الهندسي للنسب (")

المصدر: الجهاز المركزي للتعبئة العامة والإحصاء، بحوث ميز انية الأسرة بالعينة خلال الفترة (2015/1999-2000).

2. الدوال الإفاقية لإجمالي الخضر وفقاً لبيانات بحث الاخل والإففاق والإستهلاك خلا الفترة

.2015-2011/2010)

ترنكز النظرية الإقتصادية على كثثر من الدراسات الاقتصادية وعلى رأسها دراسات العالم

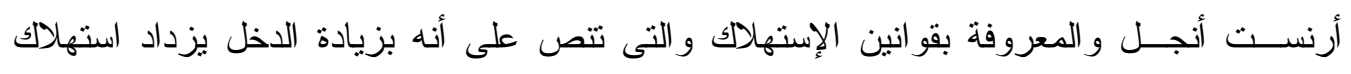

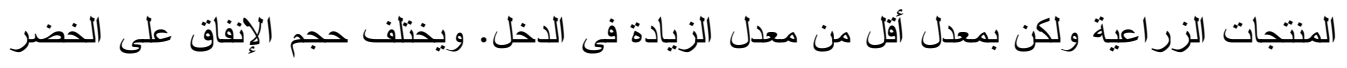

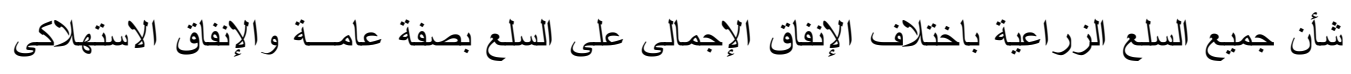

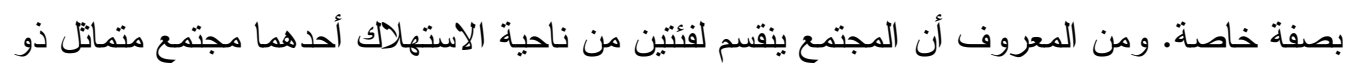
قوة شرائية منخفضة وهو المجتمع الريفى، والآخر مجتمع غير منماتل فى العادات الإستهلاكية

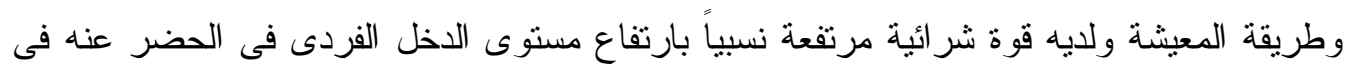


الريف و هو المجتمع الحضرى. ويختص هذا الجزء بدر سة دوال أنجل للإنفاق على الخضر ، وكذلك مرونات الطلب الإنفاقية على إجمالي الخضر في حضر وريف مصن ورئ من خلال بيانات بحوث الدخل و الإنفاق و الإستهلاك. - مرونات.

وبدر اسة العلاقة بين منوسط الإنفاق الإستهلاكى الفردي السنوى بالجنيه (متغير مسنقل)

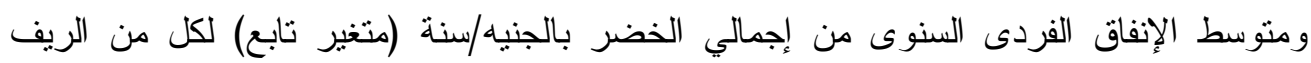

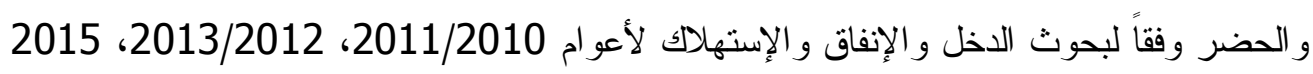

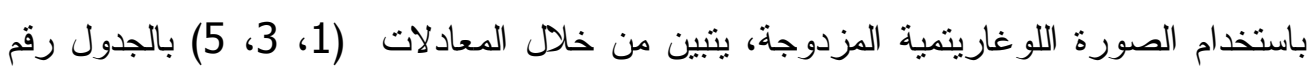
: - وجود علاقة طردية منطقية اقتصادية بين الإنفاق الإستهلاكى الفردى ومنوسط الإنفاق الفردى لإجمالي الخضر لمختلف الدوال المقدرة خلال فترة الدراسة. وقد ثبتت المعنوية الإحصائية لهذه الإنها

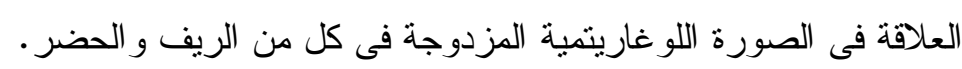

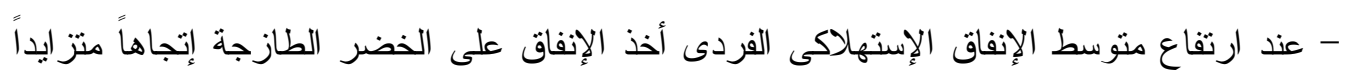

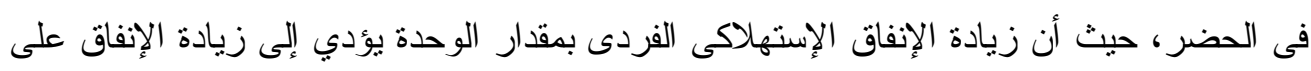

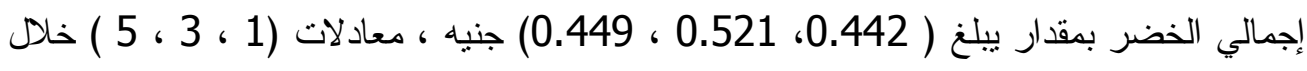

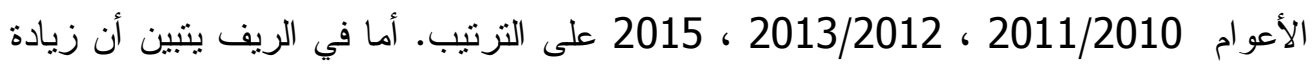

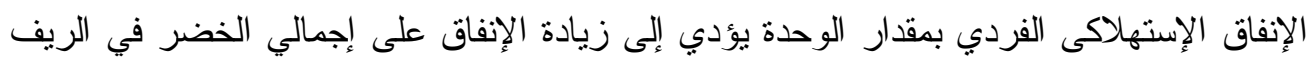

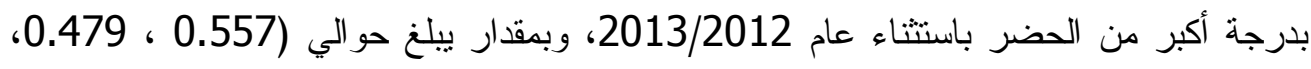

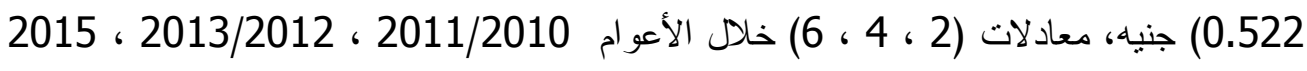
على الترتيب.

جدول رقم (2) : تقدير دو ال الطلب الإنفاقية على إجمالي الخضر فى حضر وريف مصر وفقا

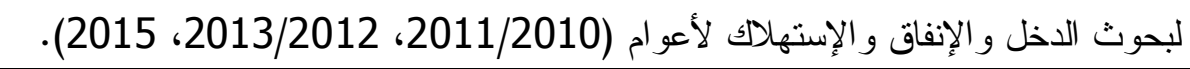

\begin{tabular}{|c|c|c|c|c|c|}
\hline $\mathbf{F}$ & $\mathbf{R}^{2}$ & المعادلة & رقم المعادلة & & السنوات \\
\hline 194 & 0.91 & $\begin{array}{r}\log y=1.15+0.442 \log X \\
(13.9)^{(*)}\end{array}$ & 1 & حضر & \multirow{2}{*}{ 울 } \\
\hline 505 & 0.96 & $\begin{array}{r}\log y=0.73+0.557 \log x \\
(22.4)^{(*)}\end{array}$ & 2 & ريف & \\
\hline 234 & 0.92 & $\begin{array}{r}\log y=0.77+0.521 \log x \\
(15.3)^{\left({ }^{*}\right)}\end{array}$ & 3 & حضر & \multirow{2}{*}{$\stackrel{m}{\stackrel{m}{o}}$} \\
\hline 111 & 0.85 & $\begin{array}{r}\log y=1.05+0.479 \log X \\
(10.5)^{\left({ }^{*}\right)}\end{array}$ & 4 & ريف & \\
\hline 129 & 0.87 & $\begin{array}{r}\log y=1.15+0.449 \log X \\
(11.3)^{\left({ }^{\circ}\right)}\end{array}$ & 5 & حضر & \multirow{2}{*}{ 뭉 } \\
\hline 223 & 0.92 & $\begin{array}{r}\log y=0.92+0.522 \log X \\
(14.9)^{(*)}\end{array}$ & 6 & ريف & \\
\hline
\end{tabular}


4- يلاحظ أن قيمة المرونة في كل السنوات موجبة وأقل من الواحد الصحيح ، أي أن الزيادة النسبية في الإنفاق الإستهلاكي (الدخل) يؤدي إلى حدوث زيادة نسبية وبدرجة أقل من الزئل الزيادة

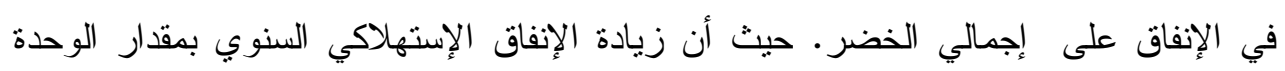

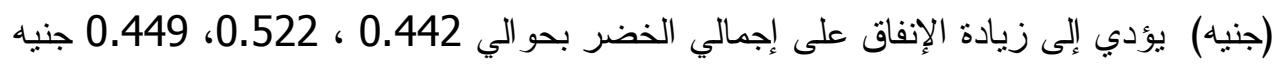

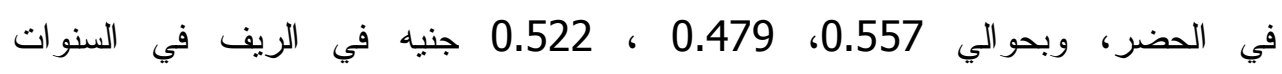

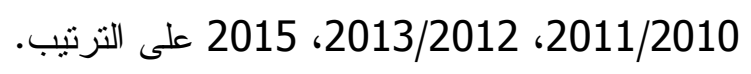

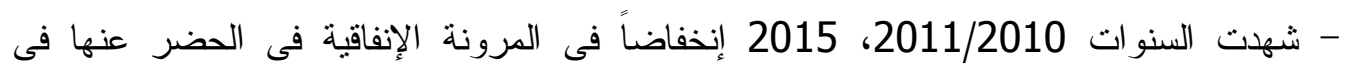
الريف، حيث بلغت فى الحضر نحو (0.442 ، 0.449) معادلات 1 ، 5 خلال السنوات السابقة

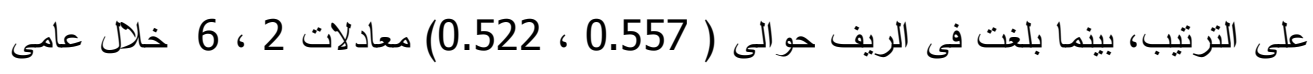

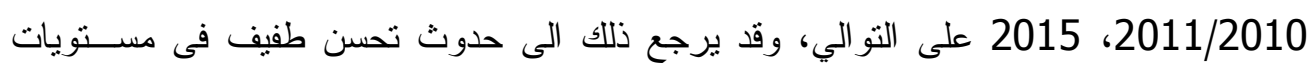

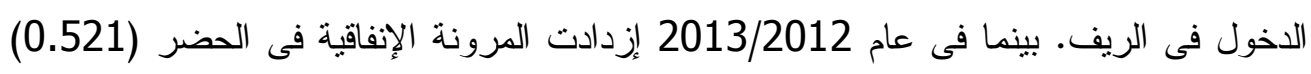

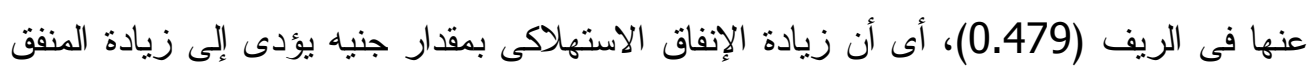
على إجمالي الخضر بنسبة 5.21\% فى الحضر، ونسبة حوالي

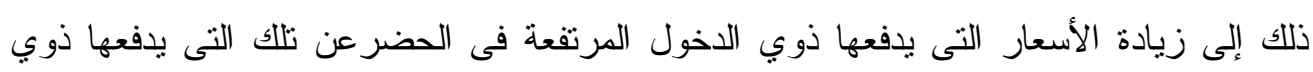

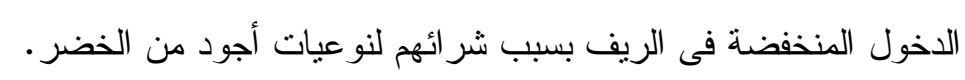

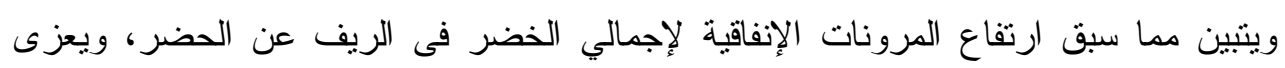

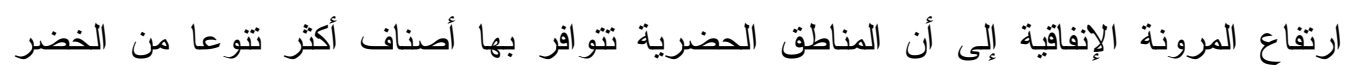
و الفاكهة وأكثر جاذبية، وهذا من شأنه انخفاض المرونة الإنلية فى الحضر مقارنة بالريف حتى فى لى

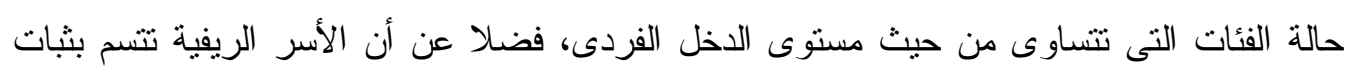
العادات الإستهلاكية.

- إرتفاع تأثثر إجمالى الإنفاق الإستهلاكى على التغيرات فى الإنفاق على إجمالي الخضر فى الريف

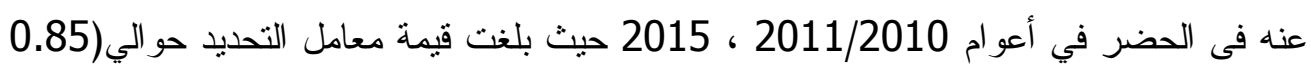

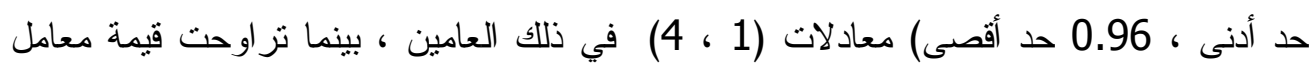

$$
\text { التحديد بين (0.87 حد ادنى ، } 0.92 \text { حد اقصى) معادلات (5 ، 3 3. 3) فى الريف. }
$$

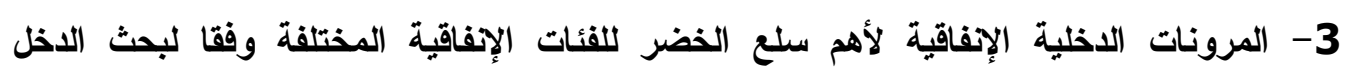

\section{والإنفاق والاستهلاك فيما بين عامي (2015/2010-2011).}

تعبر المرونة الدخلية الإنفاقية عن التغير النسبى فى الإنفاق على السلعة على التهين التغير النسبي فى النى

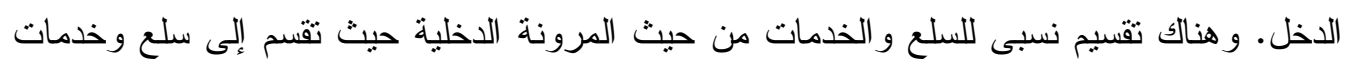

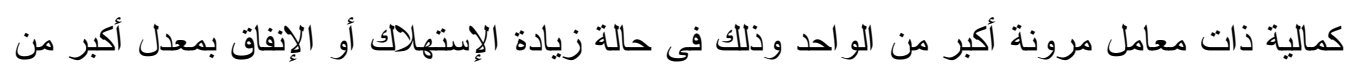

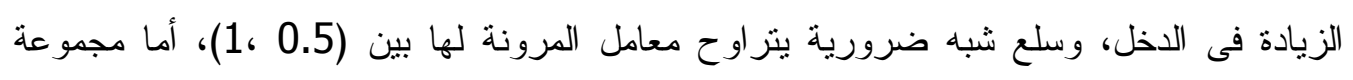

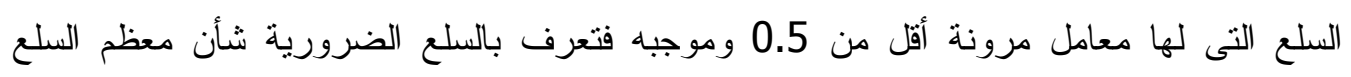

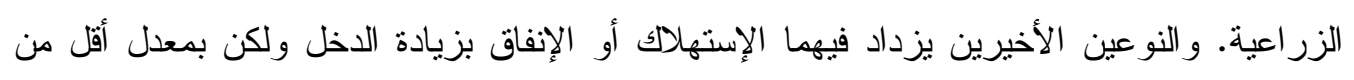
الزيادة فى الدخل حسب فئات الدخول المختلفة. 
ولما كانت الخضر من السلع الضرورية سثأنها في ذلك شأن معظم السلع الزراعية- فإن المرونة الدخلية للطلب عليها ليست واحدة عند مستويات الدخول المختلفة. لذلك قدرت المرونة الدخلية الكمبة و المرونة الدخلية الإنفاقية علي هذا المحاصيل عند فئات الدخول المختلفة. هذا، وتجدر الإثشارة إلى أن المعيار الذي استخدم عند ترتيب الأسر وفقاً للشر ائح الخمسة هو نصيب الفرد من الإنفاق السنوي، حتى لا يتم تصنيف الأسر ذات الحجم الأكبر على أنها غنية، و الحقيقة أنها

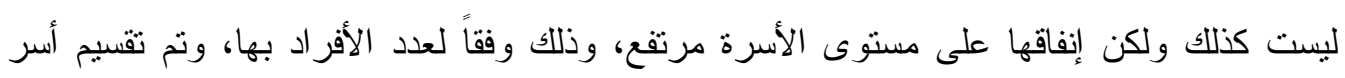

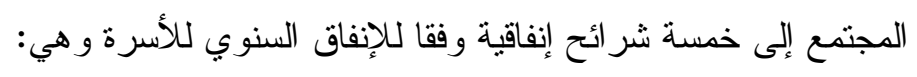

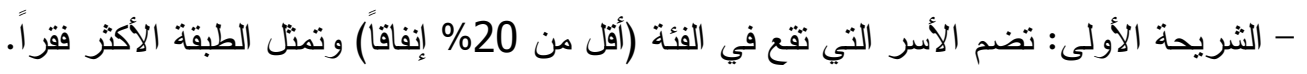

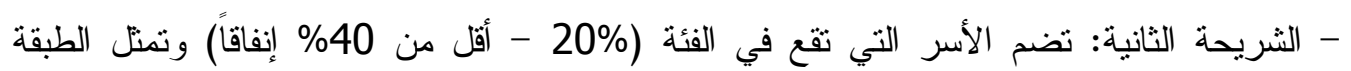
الفقيرة. - الثريحة الثالثة: تضم الأسر التي تقع في الفئة (40\% - أقل من 60\% إنفاقاً) ويطلق على هذه الفئة الطبقة المتوسطة.

- الشريحة الر ابعة: تضم الأسر التي تقع في الفئة (60\% - أقل من 80\% إنفاقاً) وهي فئة الطبقة فوق المتوسطة.

- الثريحة الخامسة: تضم الأسر التي تقع في الفئة (80\%- 100\% إنفاقاً) وتمنل هذه الفئة الطبقة

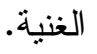

- نشير البيانات الو اردة بالجدول رقم (3) إلى نتائج تقدير ات المرونة الدخلية الإنفاقية لأهم محاصيل

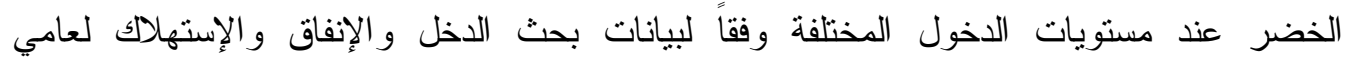

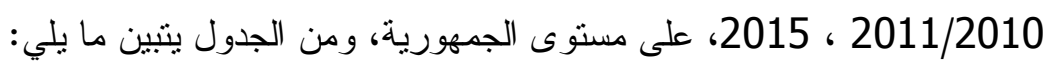
أ) بالنسبة للفئات الاخلية الأكثر انخفاضاً (الطبقة الأكثر فقراً):

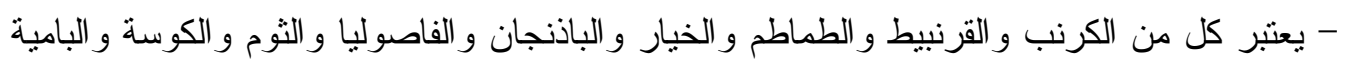

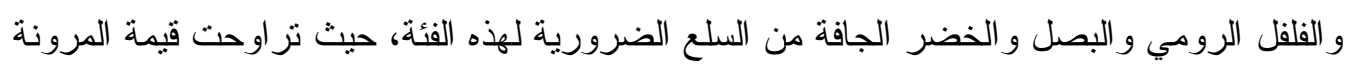
الدخلية الإنفاقية بين حوالي 0.01 كدد أدنى، وحو الي 0.46 كدد أقصي، أبي أن الطلب على هذه

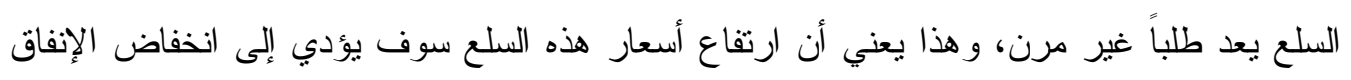
الكلي (الكمية المطلوبة) من ثلاك السلع. - يعتبر كل من البسلة والفول الأخضر و البطاطس من السلع شبه الضرورية لهذه الفئة، حيث تراوحت قيمة المرونة الدخلية الإنفاقية بين حوالي 0.53 كحد أدنى، وحوالي 0.98 كحد أقصي، ولئيل وقد يرجع ارتفاع المرونة لهذه الفئة إلى زيادة الأهمية النسبية للإنفاق على هذه السلع الئع من إجمالي

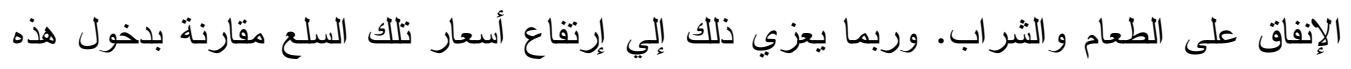

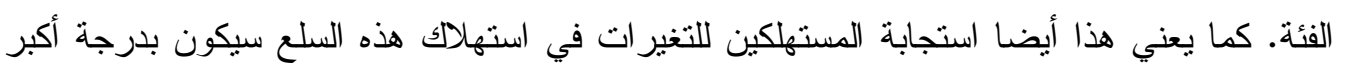

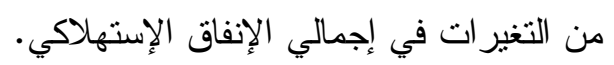
- تعتبر محاصيل اللوبيا والجزر والخضر المجدة في هذه الفئة من السلع الكمالية أي أن المرونة الإنة أكبر من الواحد الصحيح، حيث بلغت قيمة المرونة الدخلية الإنفاقية حو الي 2.53 ، 1.08 ، 3.05 
لكل سلعة على الترتيب. أب أن الطلب على هذه السلع يعتبر طلب مرن، وهذا يعني أن ارتفاع أسعار هذه السلع سوف يؤدي إلى الاستغناء عنها وبصفة خاصة في حالة الدئ الدخل المحدود. جدول رقم (3): نتائج تقدير مرونات الطلب الدخلية الإنفاقية لأهم السلع بمجموعة الخضر وفئناه وفا لبحث الاخل و الإنفاق و الاستهلاك لعامى (2011/2010 ، 2015)

\begin{tabular}{|c|c|c|c|c|c|}
\hline من 80 - 100\% & 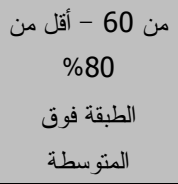 & $\begin{array}{c}\text { من } 40 \text { - أقل من } 60 \\
\text { 60بقة المتوسطة }\end{array}$ & $\begin{array}{c}\text { من 20-أقل من } 20 \\
\text { 40 الطبقة الفقيرة }\end{array}$ & أطقل 20\% الأكثر فقراً & البيان \\
\hline 0.528 & 0.209 & 0.27 & 0.33 & 0.35 & كرنب \\
\hline 0.373 & 0.210 & 0.20 & 0.43 & 0.45 & قرنبيط \\
\hline 0.122 & 0.106 & 0.15 & 0.25 & 0.27 & طماطم \\
\hline 0.810 & 0.447 & 0.51 & 0.75 & 0.44 & خيار \\
\hline 0.295 & 0.254 & 0.30 & 0.50 & 0.34 & باذنجان \\
\hline 1.449 & 0.856 & 0.75 & 1.18 & 0.98 & بسلة \\
\hline 0.092 & 0.063 & 0.08 & 0.20 & 0.46 & فاصوليا \\
\hline 3.544 & 1.306 & 2.19 & 1.50 & 2.53 & لوبيا \\
\hline 1.166 & 0.365 & 0.30 & 0.37 & 0.53 & فول اخضر \\
\hline 0.131 & 0.050 & 0.13 & 0.17 & 0.06 & ثُوم \\
\hline 0.431 & 0.190 & 0.37 & 0.23 & 0.17 & كوسة \\
\hline 0.777 & 0.261 & 0.24 & 0.44 & 0.01 & بامية \\
\hline 0.872 & 0.477 & 0.48 & 0.70 & 0.47 & فلفل رومى \\
\hline 1.661 & 1.014 & 0.94 & 1.22 & 1.08 & جزر \\
\hline 0.566 & 0.306 & 0.38 & 0.46 & 0.24 & بصل \\
\hline 0.977 & 0.906 & 1.56 & 2.90 & 3.05 & خضر مجمدة \\
\hline 0.314 & 0.221 & 0.37 & 0.47 & 0.29 & خضر جافة \\
\hline 0.428 & 0.332 & 0.47 & 0.66 & 0.56 & بطاطس \\
\hline
\end{tabular}

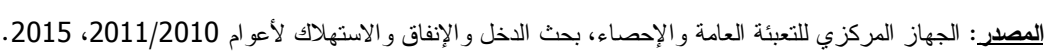

ب- بالنسبة لذوى الاخول المنخفضة (الطبقة الفقيرة): - يعتبر الطلب على كل من الكرنب و القرنبيط والطماطم و الباذنجان و الفاصوليا و الفول الأخضر و الكوسة و البامية و البصل والخضر المجمدة طلب غير مرن، أي أن هذه السلع ضرورية لهذه الفئة

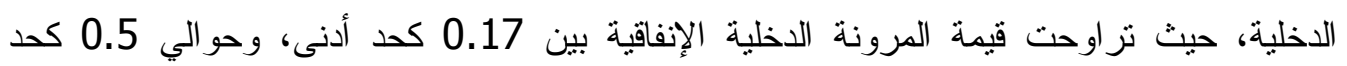
أقصى. أي أن الطلب على هذه السلع يعد طلباً غير مرن، وهذا يعني أن ارتفاع أسعار هذه السلع الأفئ سوف يؤدي إلى انخفاض الإنفاق الكلي (الكمية المطلوبة) من تلك السلع.

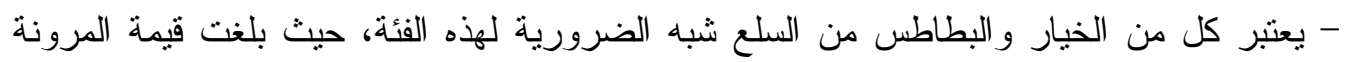

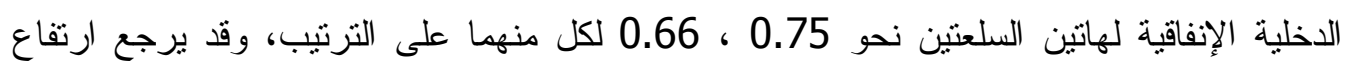
المرونة لهذه الفئة إلى زيادة الأهمية النسبية للإنفاق على هذه السلع من الإنى الجمالي الإنفاق على الطعام

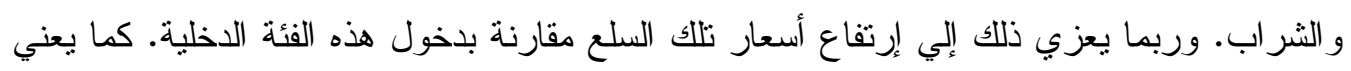

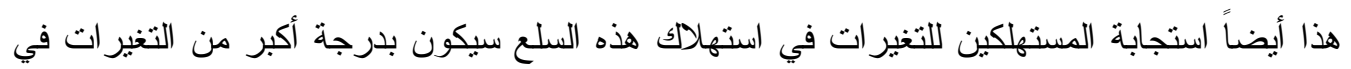
إجمالي الإنفاق الإستهلاكي. 
- تعتبر البسلة و اللوبيا والجزر والخضر المجدة في هذه الفئة من السلع الكمالية، حيث بلغت قيمة

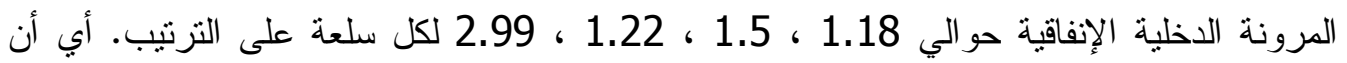
الطلب على هذه السلع يعتبر طلب مرن، وهذا يعني أن ارتفاع أسعار هذه السلع سوف يؤدي إلى الى الإستغناء عنها وبصفة خاصة في حالة الدخل المحدود. ج- بالنسبة لذوى الاخول المتوسطة (الطبقة المتوسطة): - نر اوحت قيمة المرونة الدخلية الإنفاقية لكل من الكرنب و القرنبيط و الطماطم و الباذنجان و الفاصوليا و الفول الأخضر و الثثوم والكوسة و البامية و الفلفل الرومي و البصل و الخضر الجافة و البطاطس بين

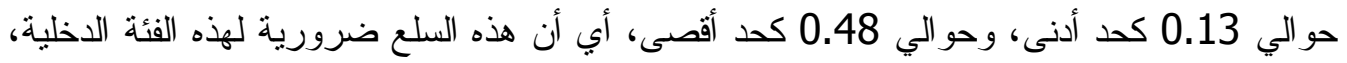

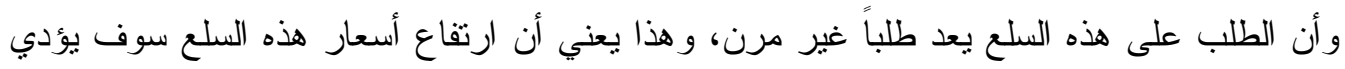
إلى انخفاض الإنفاق الكلي (الكمية المطلوبة) من تللك السلع. - يعتبر كل من الخيار والبسلة والجزر من السلع شبه الضرورية لهذه الفئة، حيث بلغت قيمة

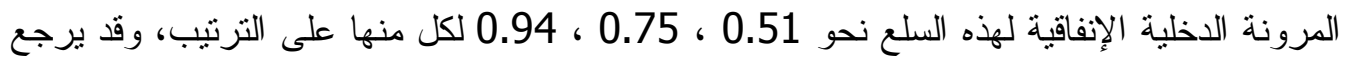

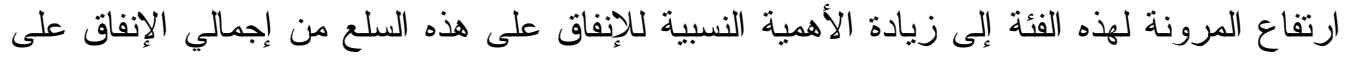

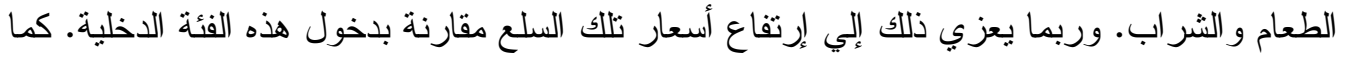
يعني هذا أيضا أن استجابة المستهلكين للتغير ات في استهلاك هذه السلع سيكون بدرجة أكبر الكبر من التغير ات في إجمالي الإنفاق الإستهلاكي. - تعتبر محاصيل اللوبيا والخضر المجمدة في هذه الفئة من السلع الكمالية، حيث بلغت قيمة المرونة الإنة الدخلية الإنفاقية لهما حو الي 2.19 ، 1.56 لكل سلعة على الترتيب. أي أن الطلب على هذه هلى السلع

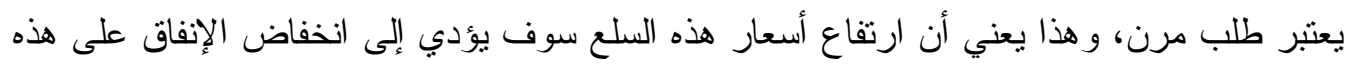
السلع أو الاستغناء عنها.

\section{د - بالنسبة لذوى الدخول فوق المتوسطة (الطبقة فوق المتوسطة):}

- تراوحت قيمة المرونة الدخلية الإنفاقية لكل من الكرنب و القرنبيط و الطماطم و الخيار و الباذنجان

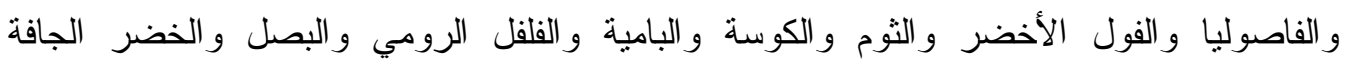

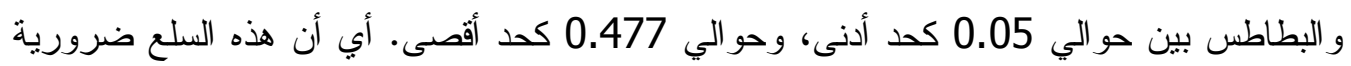
لهذه الفئة الدخلية، وأن الطلب على هذه السلع يعد طلباً غير مرن، وهذا يعني أن ارتفاع أسعار هذه السلع سوف يؤدي إلى انخفاض الإنفاق الكلي (الكمية المطلوبة) من تلك السلع. - يعتبر كل من البسلة و الخضر المجمدة من السلع شبه الضرورية لهذه الفئة، حيث بلغت قيمة الإنه

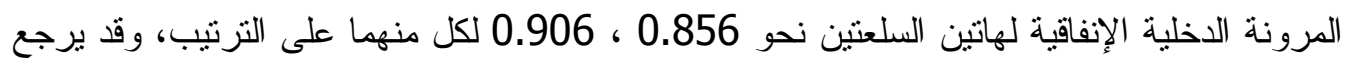

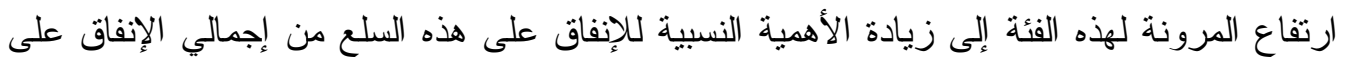

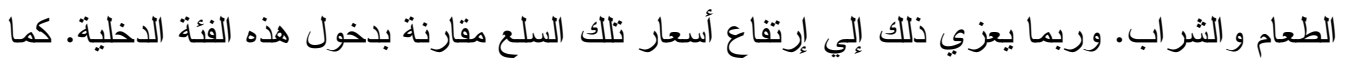

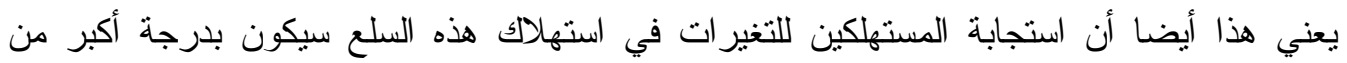

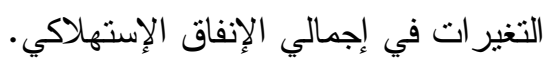


- تعتبر اللوبيا والجزر في هذه الفئة من السلع الكمالية، حيث بلغت قيمة المرونة الدخلية الإنفاقية

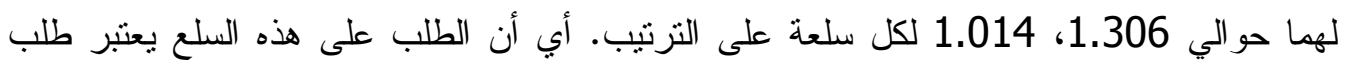

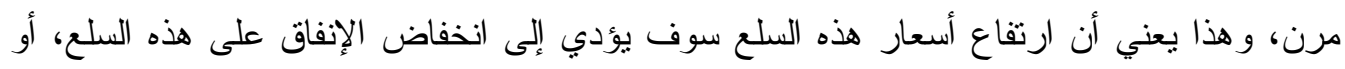
الاستغناء عنها.

ه - بالنسبة لذوى الاخول المرتفعة (الطبقة الغتية): - تر اوحت قيمة المرونة الدخلية الإنفاقية لكل من القرنبيط و الطماطم و الباذنجان و الفاصوليا و الثوم و الكوسة والخضر الجافة و البطاطس بين حو الي 0.092 كحد أدنى، وحو الي 0.431 كحد أقصى. أي أن هذه السلع ضرورية لهذه الفئة الدخلية ، وأن الطلب على هذه السلع يعد طلباً غير مرن، وهذا

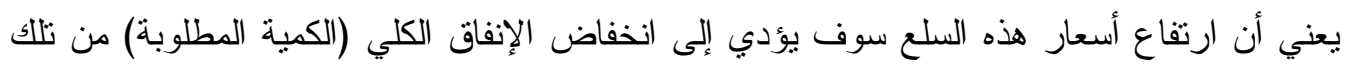

- يعتبر كل من الكرنب البسلة و الخيار و البامية و الفلفل الرومي و البصل و الخضر المجدة من السلع شبه الضرورية لهذه الفئة، حيث بلغت قيمة المرونة الدخلية الإنفاقية لهذه السلع نحو

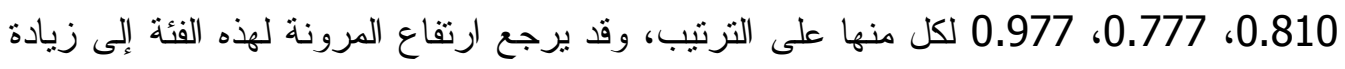

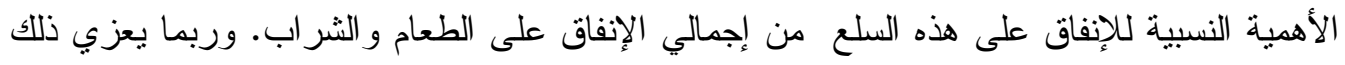

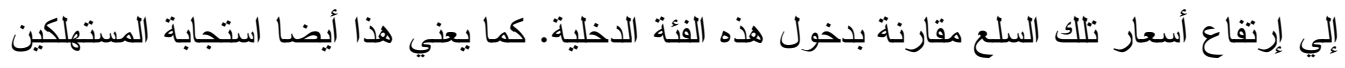
للتغير ات في استهلاك هذه السلع سيكون بدرجة أكبر من التغير ات في إجمالي الإنفاق الإستهلاكي.

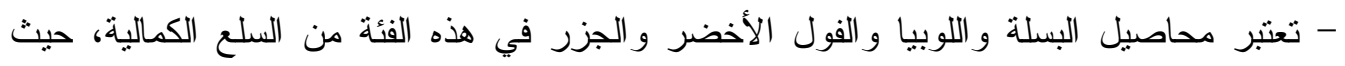

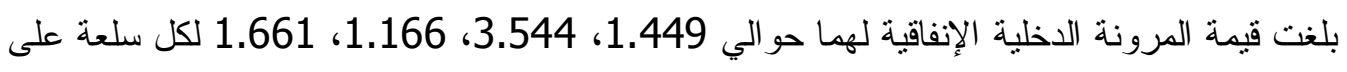

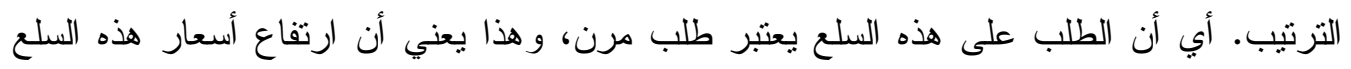
سوف يؤدي إلى انخفاض الإنفاق على هذه السلع، أو الاستغناء عنها.

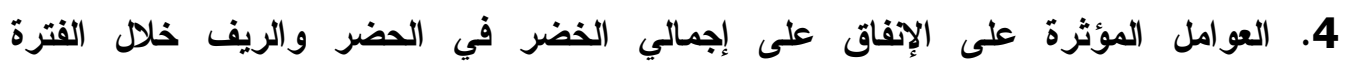
. 2015 - 2011/2010)

(أ) أثر الحالة المهنية لرب الأسرة على الإنفاق على الخضر في حضر وريف مصر:

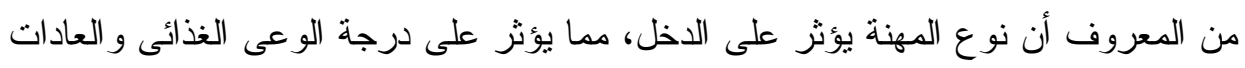

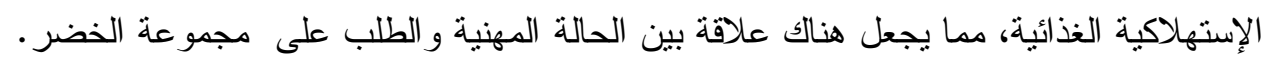
وتتثير البيانات الواردة بالجدول رقم (4) إلى تطور الإنفاق على إجمالي الخضر وفقا للحالة

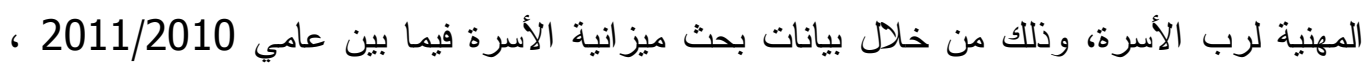

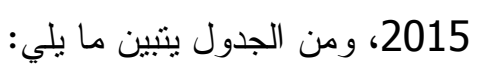
- بصفة عامة تتجه نسبة الإنفاق على إجمالي الخضر من إجمالي الإنفاق على الطعام و الثراب نحول

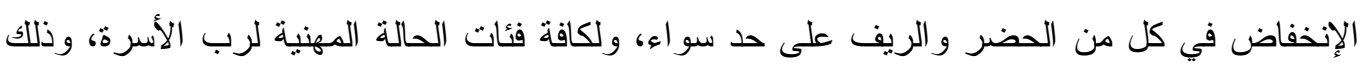
فيما بين عامي 2011/2010 ، 2015.

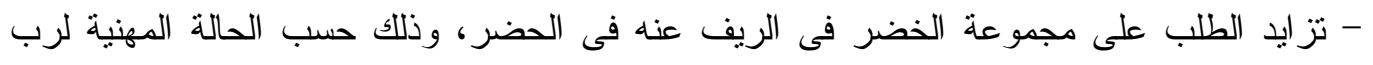

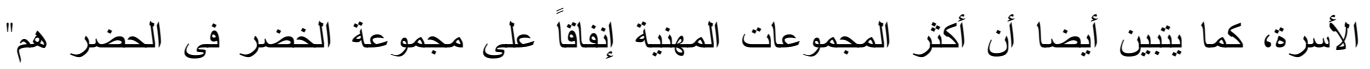


المز ارعون وعمال الزر اعة و العاملون بالصيد" ، يليها عمال المهن العادية، وذلك على الرغم من اتجاه هذا الإنفاق نحو الإنخفاض، حيث بلغ نحو 7.5\%، 5.6\% من إجمالي الإنفاق على الطعام والثر اب اب في أعوام 2011/2010، 2015 على الترتيب لهجموعة المزارعون وعمال الزراعة و العاملون بالصيد، في حين بلغت نحو 7\%، 5\% لمجموعة عمال المهن العادية لنفس العامين على التزتيب. أما اقل المجموعات المهنية إنفاقاً على مجموعة الخضر فهى "رجال التشريع وكبار المسؤولين و المديرون"، و أيضا أصحاب المهن العلمية، وقد يرجع ذلك لارتفاع مستوى دخول أفراد هذه الفئة

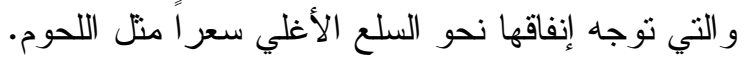
أما بالنسبة للريف فيعتبر أيضا مجموعة" المز ارعون وعمال الزر اعة و العاملون بالصيد"، يليها الحرفيون هم الأكثر إنفاقاً على مجموعة الخضر وذلك على الرغم من اتجاه هذا الإنفاق نحو الإنخفاض، حيث بلغ نحو 7.9\%، 6.9\% من إجمالي الإنفاق على الطعام و الشراب في أعو ام

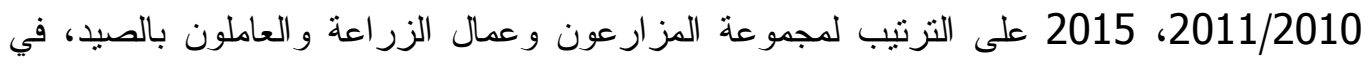
حين بلغت نحو 7.9\%، 6.6\% لمجموعة الحرفيين لنفس العامين على الترنيب. أما اقل المجموعات ولمات المهنية إنفاقاً على مجموعة الخضر في الريف فهم أصحاب المهن العلمية، ومجموعة "رجال التشريع وكبار المسؤولين و المديرون" وقد يرجع ذلك لإرتفاع مستوى دخول أفر اد هذه الفئة و التي نوجه إنفاقها

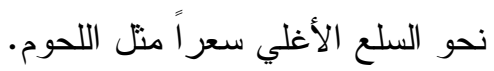
جدول رقم (4): الأهمية النسبية للإنفاق على إجمالي الخضر وفقا للحالة المهنية لرب الأسرة في حضر وريف مصر خلا الفترة (2011/2010 - 2015).

\begin{tabular}{|c|c|c|c|c|}
\hline \multicolumn{2}{|c|}{ الريف } & \multicolumn{2}{|c|}{ الحضر } & \multirow{2}{*}{ فئات الحالة المهنية } \\
\hline 2015 & $2010 / 11$ & 2015 & $2010 / 11$ & \\
\hline 5.0 & 6.6 & 3.0 & 4.0 & رجال التثريع وكبار المسؤلين والمديرون \\
\hline 5.2 & 6.8 & 2.8 & 4.0 & الأحصائيون (أصحاب المهن العلمية) \\
\hline 5.4 & 6.9 & 4.1 & 5.2 & الفنيون ومساعدو الاخصائيون \\
\hline 5.6 & 7.3 & 4.5 & 5.5 & القائمون بالأعمال الكتابية \\
\hline 6.2 & 7.2 & 4.7 & 6.0 & العاملون فى الخدمات ومحلات البيع \\
\hline 6.9 & 7.9 & 5.6 & 7.5 & المزارعون وعمال الزراعة والعاملون بالصيد \\
\hline 6.6 & 7.9 & 5.2 & 6.4 & الحرفيون \\
\hline & & & & عمال تشغيل المصاتع قمشظفوا الماكينات وعمال تجميع مكونات \\
\hline 6.5 & 7.7 & 5.0 & 6.2 & الاتتاج \\
\hline 6.6 & 7.9 & 5.4 & 7.0 & عمال المهن العادية \\
\hline 6.4 & 7.6 & 4.0 & 5.3 & أفراد لا ينطبق عليهم بيان المهنة \\
\hline 6.0 & 7.4 & 4.3 & 6.0 & | \\
\hline
\end{tabular}
لمصدر: الجهاز المركزي للتعبئة العامة و الإحصاء، بحث الدخل و الإنفاق و الاستهلاك لأعو ام 2011/2010، 2015.

(ب) أثر الحالة العملية لرب الأسرة على الإنفاق على إجمالي الخضر في حضر وريف مصر :

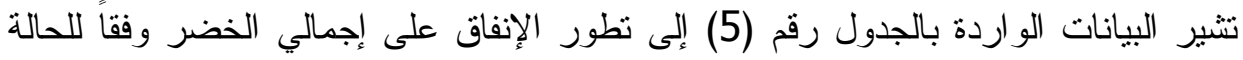

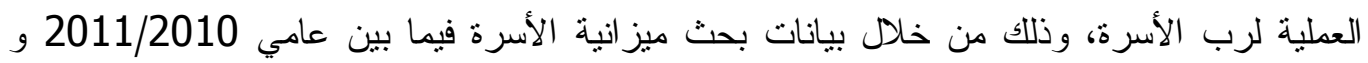
2015، ومن الجدول ينتين ما يلي: - يزداد الطلب على إجمالي مجموعة الخضر فى الريف عنه فى الحضر وفقاً للحالة العملية لرب ملاب الأسرة، إذ بلغ متوسط نسبة الإنفاق السنوى الفردى على إجمالي الخضر من إجمالي الإنفاق على فلى فلى إلى

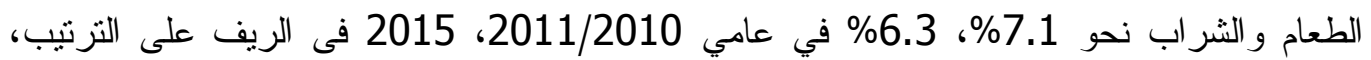
ونحو 5.3\%، 4.1\% في الحضر خلال نفس العامين على الترتيب. 
- بصفه عامة تتجه نسبة الإنفاق على إجمالي الخضر من إجمالي الإنفاق على الطعام و الثراب وذلك

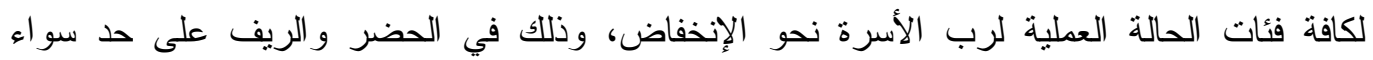

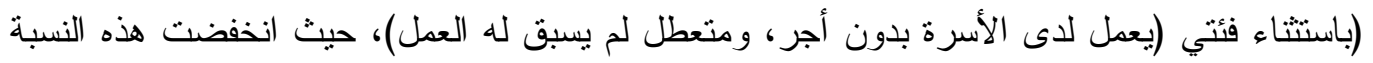

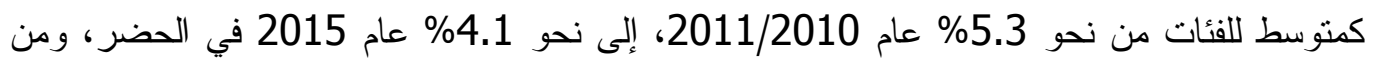
نحو 7.1\% عام 2011/2010، إلى نحو 6.5\% وذللك في الريف، وربما يرجع ذلك إلى ارتفاع أسعار الأنو اع المختلفة من الخضر مقارنة بالزيادة في الدخل. - بالنسبة للحضر ، تعتبر فئتي (المتعطل الذي لم يسبق له العمل، و العاملين لدى الأسرة بدون أجر ) هما أكثر الفئات طلباً لإجمالي الخضر، نعيثر هيث بلغت نسبة الإنفاق على إجمالي الخضر من إجمالي الإنفاق

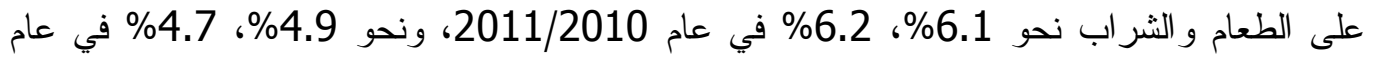
2015، وربما يعزى ذلك إلى انخفاض أجور هذه الفئة مقارنة بالفئات الأخرى. أما أقل الفئات إنفاقاً

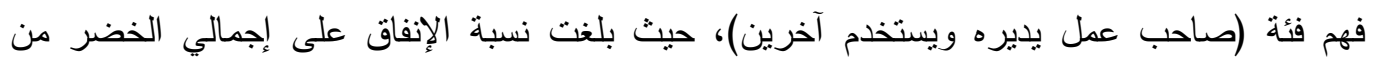
إجمالي الإنفاق على الطعام و الثراب نحو 4.4\%، 3.3\% وذللك في عامي 2011/2010،

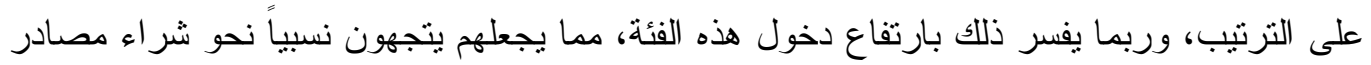
بروتين مرتفعة الثمن ومن أهمها اللحوم و الأسماك و الدو اجن. - بالنسبة للريف تعتبر فئتي (خارج القوي البشرية، ومن يعمل لحسابه ولا يستخدم أحد) هما أكثر

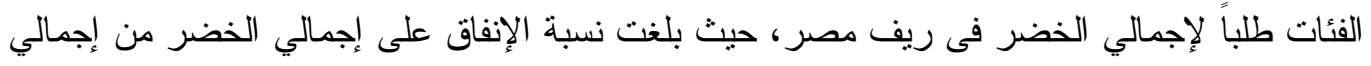

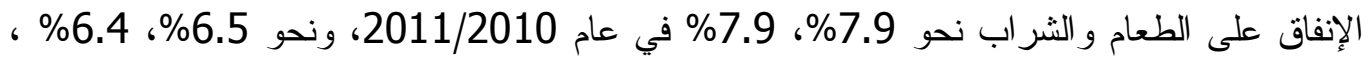
في عام 2015 لكل فئة على الترنيب، وربما يعزى ذللك إلى انخفاض أجور هذه الفئة مقارنة بالفئات

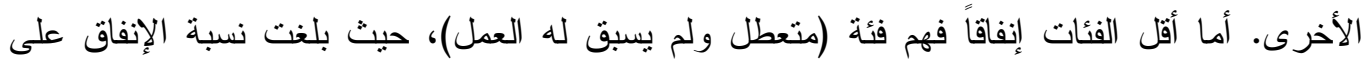

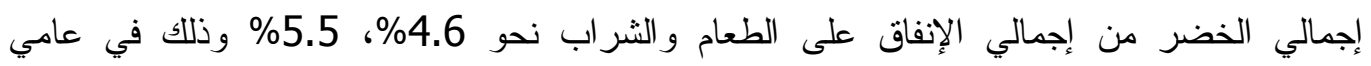
2011/2010، 2015 على الترتيب، وربما يفسر ذلك بارتفاع دخول هذه الفئة.

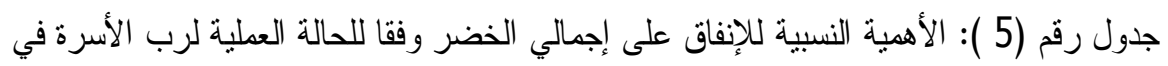
حضر وريف مصر خلا الفترة (2011/2010 - 2015).

\begin{tabular}{|c|c|c|c|c|}
\hline \multicolumn{2}{|c|}{ الريف } & \multicolumn{2}{|c|}{ الحضر } & \multirow{2}{*}{ الحالة العملية لرب الأسرة } \\
\hline 2015 & $2010 / 11$ & 2015 & $2010 / 11$ & \\
\hline 6.1 & 7.5 & 4.1 & 5.3 & يعل بأجر نقدى \\
\hline 6.2 & 7.4 & 3.3 & 4.4 & صلحب عمل ويديره ويستخدم آخرين \\
\hline 6.4 & 7.9 & 4.7 & 6.2 & يعمل لحسابه ولا يستذام أحد \\
\hline 7.5 & 7.4 & 3.7 & 5.1 & يعمل لاى الأسرة بدون أجر \\
\hline 6.1 & 7.2 & 4.4 & 5.2 & متعطل سبق له العمل \\
\hline 5.5 & 4.6 & 4.9 & 6.1 & متعطل لم يسبق له العل \\
\hline 6.3 & 7.4 & 4.1 & 5.3 & خارج قوة العمل \\
\hline 6.5 & 7.9 & 3.9 & 5.1 & خارج القوى البشرية \\
\hline 6.3 & 7.1 & 4.1 & 5.3 & المتوسط" \\
\hline
\end{tabular}


(ج) أثر الحالة التعليمية لرب الأسرة على الإنفاق على إجمالي الخضر في حضر وريف مصر:

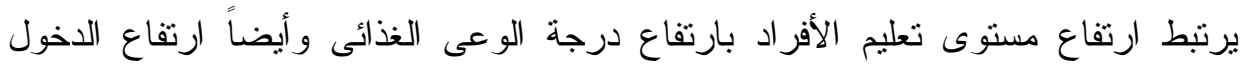

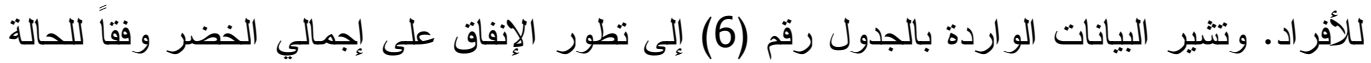

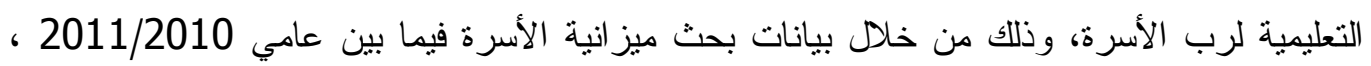
2015، ومن الجدول ينتين ما يلي:

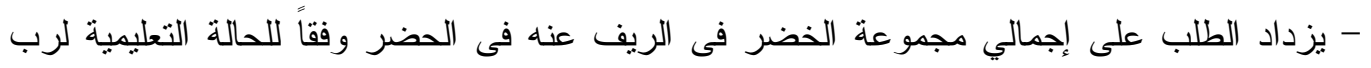

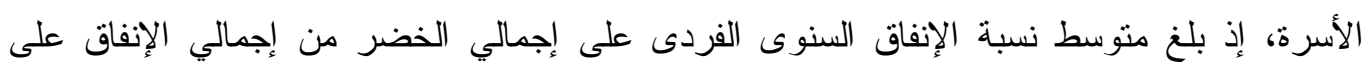

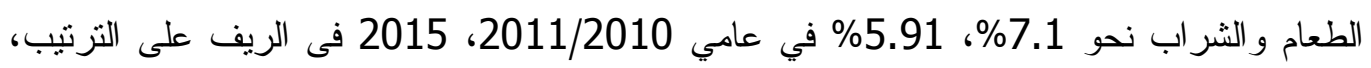
ونحو 5.41\%، 4.21\% في الحضر خلال نفس العامين على التزتيب. - بصفة عامة تتجه نسبة الإنفاق على إجمالي الخضر من إجمالي الإنفاق على الطعام و الثراب وذللك

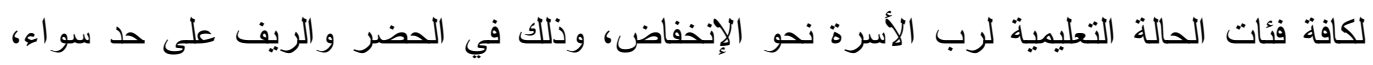

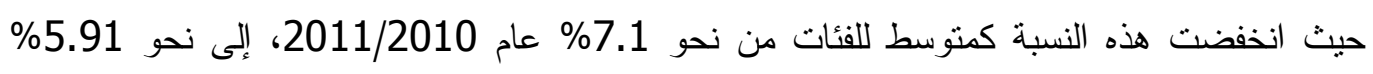

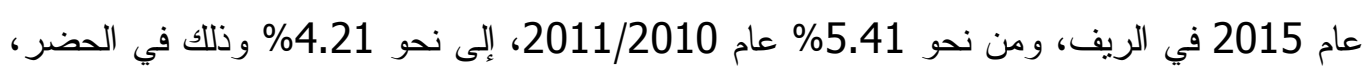

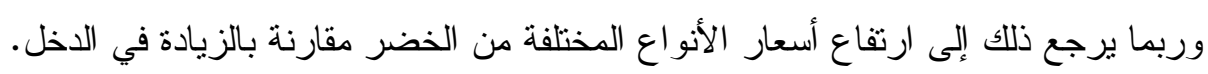

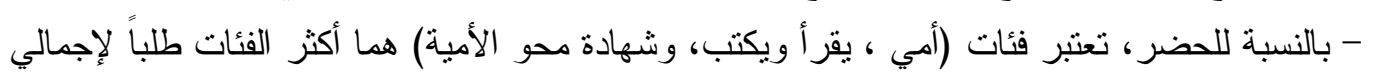

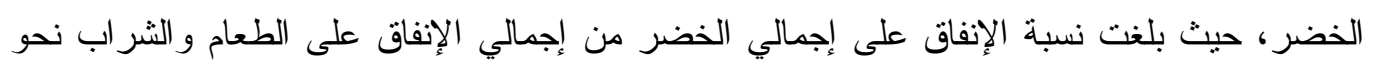

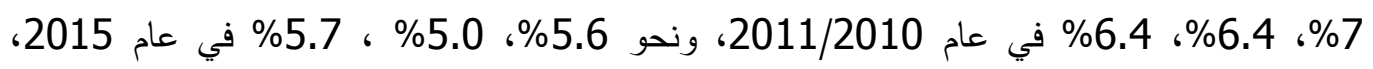
وربما يعزى ذلك إلى انخفاض أجور هذه الفئة مقارنة بالفئات الأخرى. أما أقل الفئات إنفاقًا فهم فئة

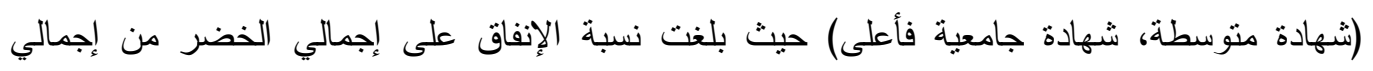

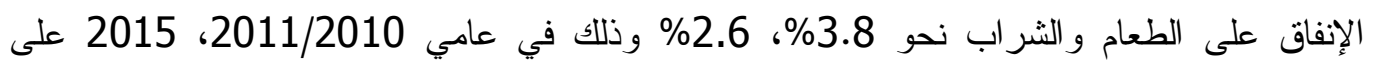
الترنيب، وربما يفسر ذلك بارتفاع دخول هذه الفئة، مما يجعلهم يتجهون نسبياً نحو شر اء مصاء ودادر بروتين مرتفعة الثمن ومن أهمها اللحوم و الدو اجن و الأسماك.

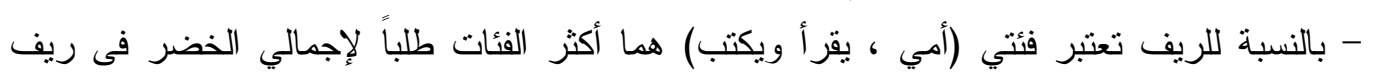

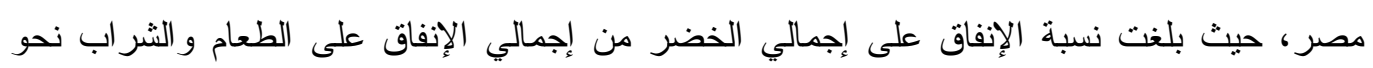

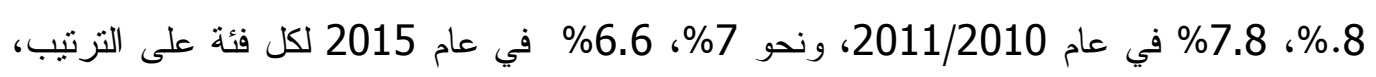
وربما يعزى ذلك إلى انخفاض أجور هذه الفئة مقارنة بالفئات الأخرى. أما أقل الفئات إنفاقاً فهم فئة الفّا (الأنشطة الإدارية والثقنية المتخصصة)، حيث بلغت نسبة الإنفاق على إجمالي الخضر من إجمالي

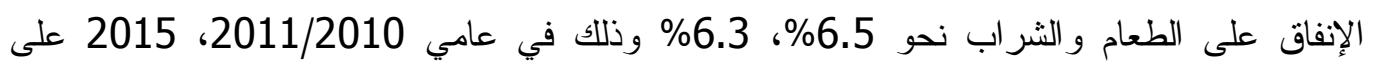


جدول رقم (6): الأهمية النسبية للإنفاق على الخضر وفقا للحالة التعليمية لرب الأسرة في حضر وريف مصر خلال الفترة (2011/2010 - 2015).

\begin{tabular}{|c|c|c|c|c|}
\hline \multicolumn{2}{|c|}{ الريف } & \multicolumn{2}{|c|}{ الحضر } & \multirow{2}{*}{ فئات الحالة التعليمية لرب الأسرة } \\
\hline 2015 & $2010 / 11$ & 2015 & $2010 / 11$ & \\
\hline 7.0 & 8.0 & 5.6 & 7.0 & أمى \\
\hline 6.6 & 7.8 & 5.0 & 6.4 & يقرأ ويكتب \\
\hline 6.7 & 7.4 & 5.7 & 6.4 & شهادة محو الأمية \\
\hline 6.3 & 7.3 & 4.6 & 6.0 & شهادة أقل من المتوسط \\
\hline 5.9 & 7.4 & 4.3 & 5.5 & شهادة متوسطة \\
\hline 5.3 & 6.5 & 3.8 & 5.3 & شهادة فوق المتوسط \\
\hline 4.9 & 6.3 & 2.6 & 3.5 & شهادة جامعىية فأعلى \\
\hline 5.91 & 7.10 & 4.21 & 5.41 & المتوسط" \\
\hline
\end{tabular}

المصدر: الجهاز المركزي للتعبئة العامة والإحصاء، بحث الدخل و الإنفاق و الاستهلاك لأعوام 2011/2010، 2015. (ه) أثر إنفاق عدد أفراد الأسرة على إجمالي الخضر في حضر وريف مصر : من المتوقع نظرياً وجود علاقة طردية بين حجم الأسرة ومتوسط الإنفاق السنوى للفرد على الإلى السلعة

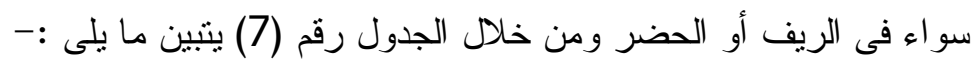

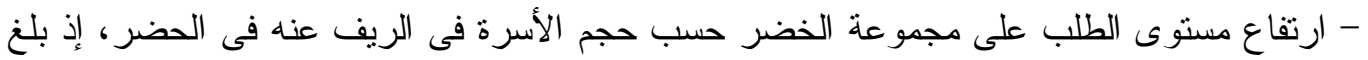
متوسط الإنفاق الفردى السنوى على مجموعة الخضر من إجمالي الإنفاق على الطعام و الثراب نحو

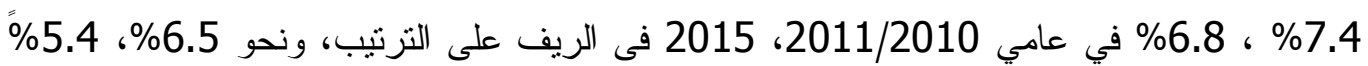
في الحضر خلال نفس العامين على الترتيب.

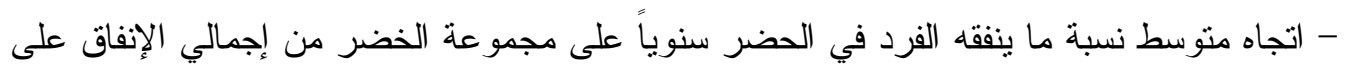

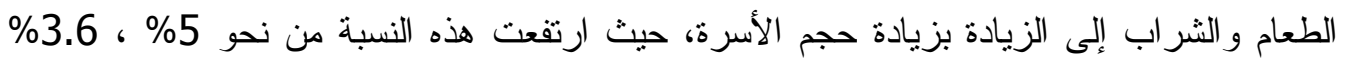

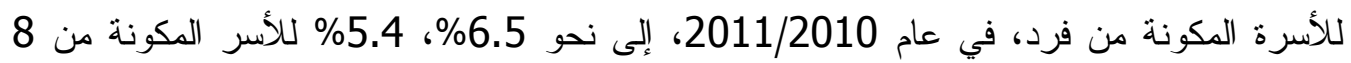
أفراد فأكثر في عام 2015. أما في الريف فقد اتجهت هذه النسبة نحو الإنخفاض من نحو 8.2 إلى نحو 7.4\% عام 2011/2010، أما في عام 2015 فلم تتأثر النسبة المئوية للإنفاق السنوى الإنى على مجموعة الخضر إلى إجمالى الإنفاق على الطعام و الثراب بزيادة حجم الأسرة، حيث بلى بلغت

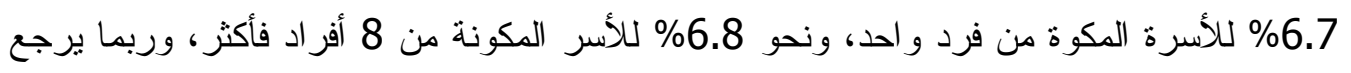

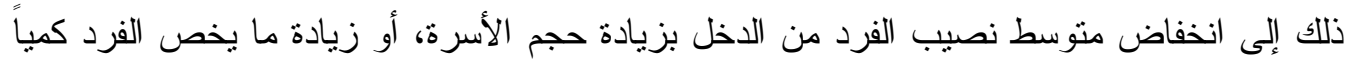
و الذى لا يعزى لأى عامل آخر سوى زيادة عدد أفر اد الأسرة.

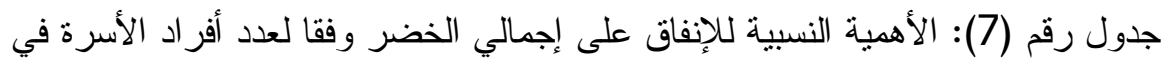
حضر وريف مصر خلال الفترة (2011/2010 - 2015).

\begin{tabular}{|c|c|c|c|c|}
\hline \multicolumn{2}{|c|}{ الريف } & \multicolumn{2}{|c|}{ الحضر } & \multirow{2}{*}{ عدد أفراد الأسرة } \\
\hline 2015 & $2010 / 11$ & 2015 & $2010 / 11$ & \\
\hline 6.7 & 8.2 & 3.6 & 5.0 & فرد \\
\hline 6.1 & 7.4 & 3.8 & 4.8 & 2 \\
\hline 5.9 & 7.4 & 3.8 & 4.9 & 3 \\
\hline 6.2 & 7.6 & 3.8 & 5.2 & 4 \\
\hline 6.1 & 7.6 & 3.9 & 5.3 & 5 \\
\hline 6.3 & 7.5 & 4.6 & 5.6 & 7- 6 \\
\hline 6.8 & 7.4 & 5.4 & 6.5 & 8 فأكثر \\
\hline
\end{tabular}


6. منحنى لورنز لقياس توزيع الاخل (الإفاق) لمجموعة الخضر فى ريف وحضر مصر:

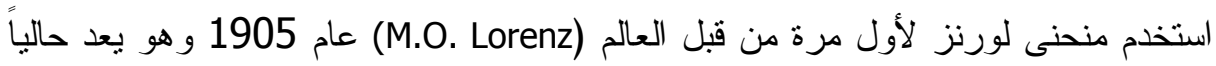

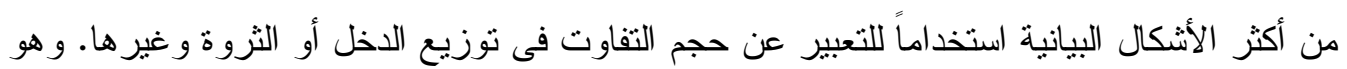

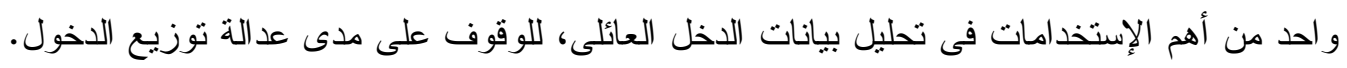

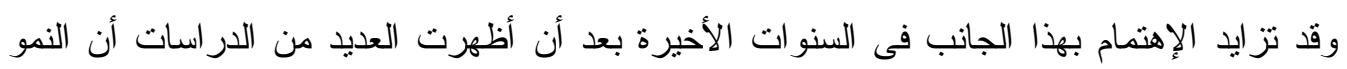

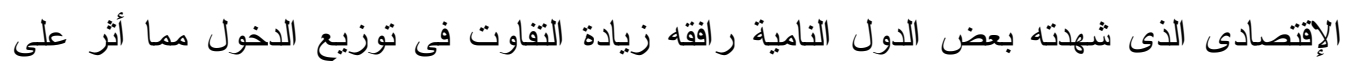
الطلب الكلى وحجم الإستهلالك و الإنفاق الإستهلاكى.

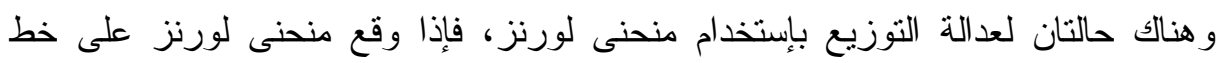

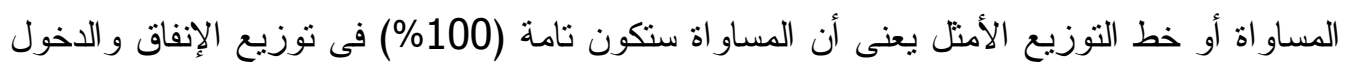

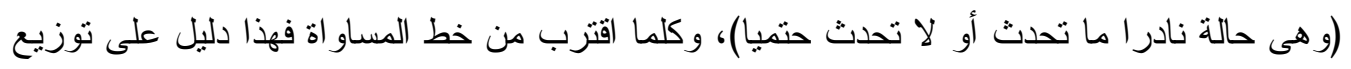

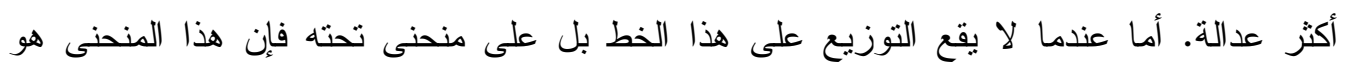

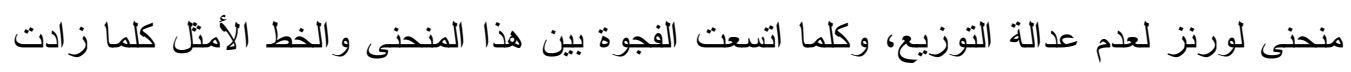
عدم عدالة التوزيع و العكس صحيح.

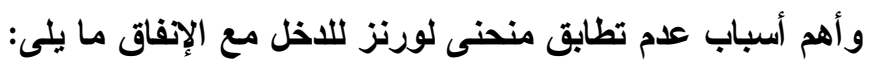

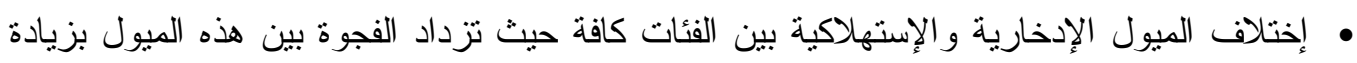

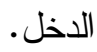
• • اختلاف العادات الإنتهلاكية فى المجتمع التى تخلق فجوة بين مستوى الدخل ومستوى الإستهلاك.

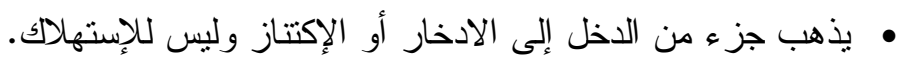

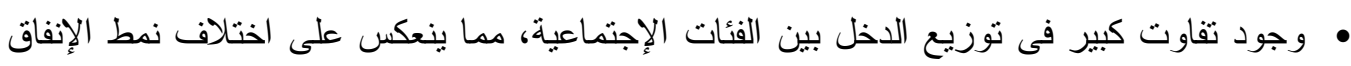
و وعلى الإدخار و الإنتهلاك الحاضر و الإستهلالك المستقبلى. • • لا تعتد الأسرة فقط على الدخل فى تلبية احتياجاتها. • • اختلاف حاجات المستهلك ورغباته وطرق تلبيتها وأسلوب تحقيق هذه الرغبات الرغات. وفى ضوء ماسبق تم المقارنة بين الحضر والريف من حيث إجمالى الإنفاق الإنتهلاكى و أيضا من التهات

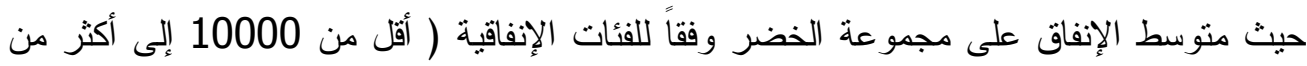
. 100000

\section{5- قياس عدالة التوزيع لكتوسط الإففاق الإستهلاكى على إجمالي الخضر:}

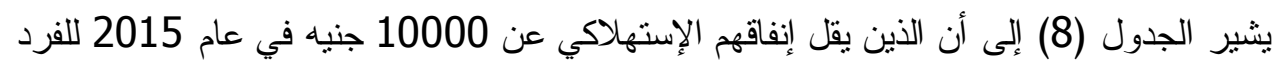

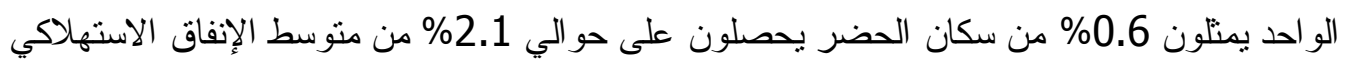

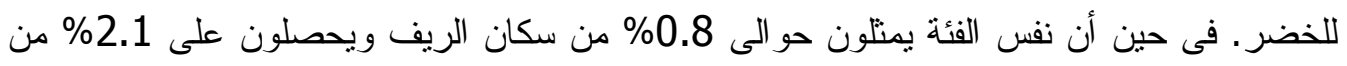

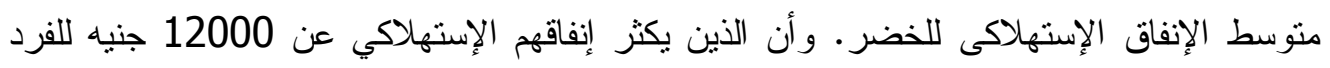
الواحد يمنلون 0.8\% من سكان الحضر ويحصلون على حوالي 2.8\% من متوسط الإنفاق

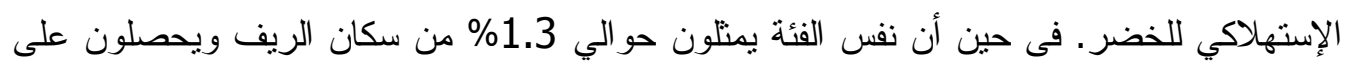

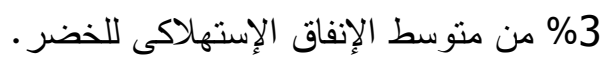


كما أن الذين يكثر إنفاقهم الإستهلاكي عن 30000 جنيه للفرد الو احد يمنلون 14\% من سكان الحضر يحصلون على حو الي 5.6\% من منوسط الإنفاق الاستهلاكي للخضر . فى حين أن نفس الفئة تمثل حو الى 16.1\% من سكان الريف ويحصلون على 5.4\% من إجمالى الإنفاق الإستهلاكى.

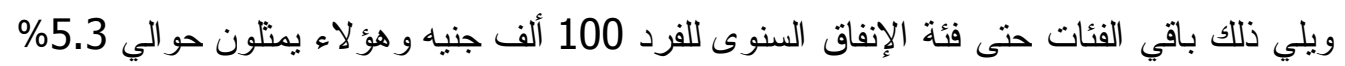

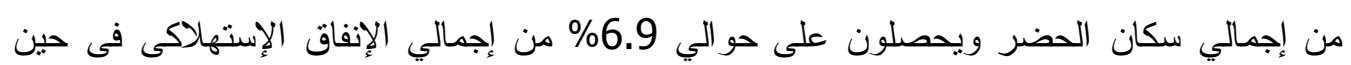
يمثلون حو الى 1.3\% من سكان الريف ويحصلون على 6.9\% من إجمالى الإنفاق الإستهلاكى.

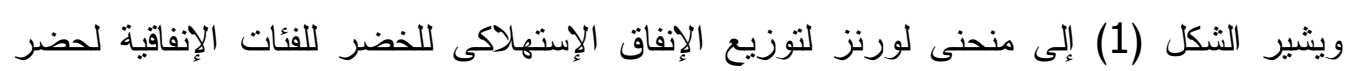

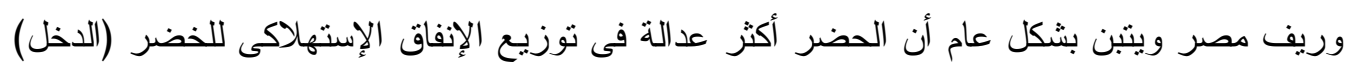

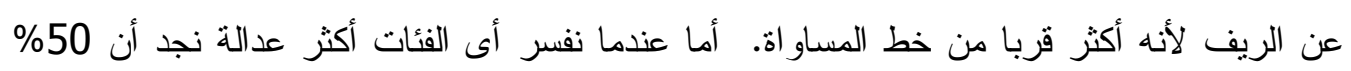

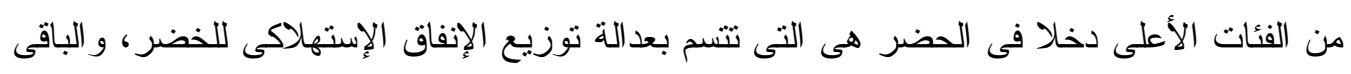

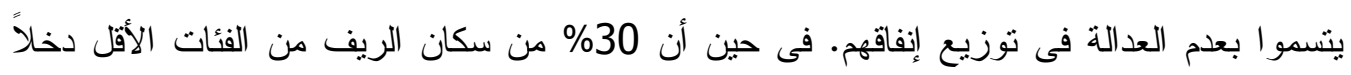

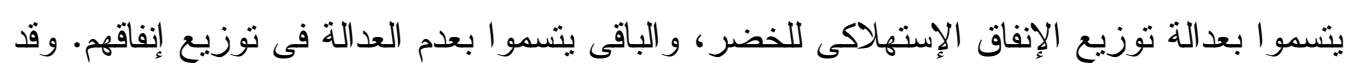

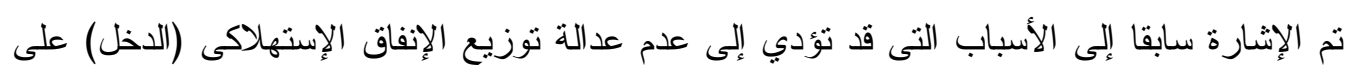
فئات المجتمع. جدول رقم (8) : التوزيع النسبى للإنفاق الإستهلاكى للخضر

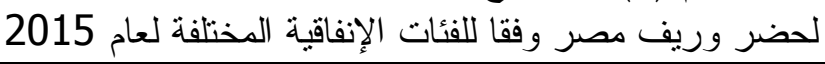

\begin{tabular}{|c|c|c|c|c|c|c|c|c|}
\hline \multicolumn{2}{|c|}{ ريف } & \multicolumn{2}{|c|}{ حضر } & \multicolumn{2}{|c|}{ ريف } & \multicolumn{2}{|c|}{ حضر } & \multirow[b]{2}{*}{ الفئات الإففاقية } \\
\hline 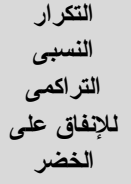 & $\begin{array}{c}\text { \% الإستهلاكى } \\
\text { للخضر }\end{array}$ & للإنفاق على الترى التى النسبى & الإستهلاكى \% الخضر & التلن التبمى & $\begin{array}{c}\text { للأفراد } \\
\text { \% }\end{array}$ & التلزراكمى التكرة & 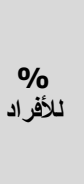 & \\
\hline 2 & 2.1 & 2 & 2.1 & 0.8 & 0.8 & 0.6 & 0.6 & 10000- \\
\hline 5 & 2.6 & 5 & 3.0 & 1.6 & 0.8 & 1.2 & 0.6 & -10000 \\
\hline 8 & 3.0 & 8 & 2.8 & 3.0 & 1.3 & 2.0 & 0.8 & -12000 \\
\hline 11 & 3.3 & 11 & 3.3 & 5.2 & 2.3 & 3.5 & 1.4 & -14000 \\
\hline 15 & 3.6 & 15 & 3.6 & 8.4 & 3.2 & 5.4 & 1.9 & -16000 \\
\hline 18 & 3.9 & 19 & 4.0 & 13.1 & 4.7 & 8.0 & 2.6 & -18000 \\
\hline 23 & 4.2 & 23 & 4.3 & 18.8 & 5.7 & 11.7 & 3.7 & -20000 \\
\hline 27 & 4.5 & 28 & 4.5 & 26.4 & 7.6 & 15.8 & 4.2 & -22000 \\
\hline 32 & 4.7 & 32 & 4.9 & 33.8 & 7.4 & 20.8 & 5.0 & -24000 \\
\hline 37 & 4.9 & 37 & 4.9 & 41.1 & 7.3 & 26.5 & 5.7 & -26000 \\
\hline 42 & 5.2 & 42 & 5.0 & 48.4 & 7.3 & 32.7 & 6.2 & -28000 \\
\hline 47 & 5.4 & 48 & 5.6 & 64.5 & 16.1 & 46.8 & 14.0 & -30000 \\
\hline 53 & 5.9 & 54 & 5.8 & 75.2 & 10.8 & 58.3 & 11.5 & -35000 \\
\hline 60 & 6.2 & 60 & 6.2 & 82.6 & 7.3 & 67.1 & 8.8 & -40000 \\
\hline 66 & 6.4 & 66 & 6.4 & 87.9 & 5.4 & 73.7 & 6.6 & -45000 \\
\hline 73 & 6.7 & 73 & 6.6 & 91.0 & 3.1 & 79.1 & 5.4 & -50000 \\
\hline 79 & 6.8 & 79 & 6.4 & 93.4 & 2.4 & 82.9 & 3.8 & -55000 \\
\hline 86 & 6.7 & 86 & 6.8 & 96.1 & 2.7 & 88.1 & 5.2 & -60000 \\
\hline 93 & 7.0 & 93 & 7.0 & 98.7 & 2.6 & 94.7 & 6.6 & -70000 \\
\hline 100 & 6.9 & 100 & 6.9 & 100 & 1.3 & 100 & 5.3 & -100000 \\
\hline & 100 & & 100 & & 100 & & 100 & المجموع \\
\hline
\end{tabular}




$$
\text { شكل رقم (1) : منحنى لورنز لتوزيع الإنفاق الإستهلاكى للخضر الإنفاقية لحضر وريف مصر }
$$

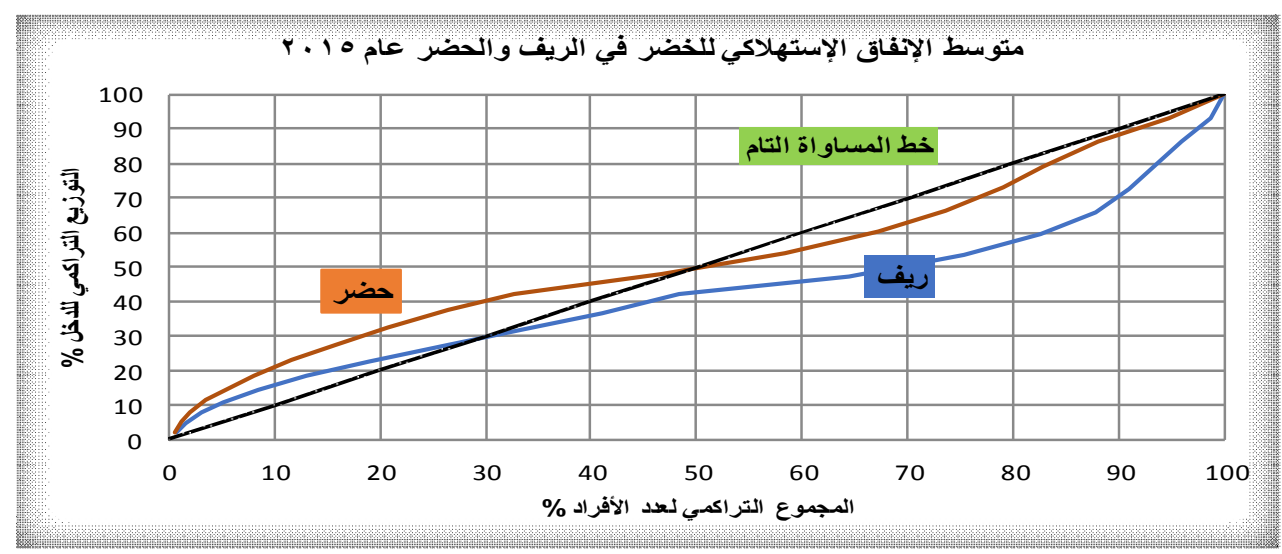

\section{الملخص والتوصيات}

تمنلت مشكلة الدر اسة حول التغيرات فى الإنفاق الإستهلاكى على مجموعة الخضر وذللك

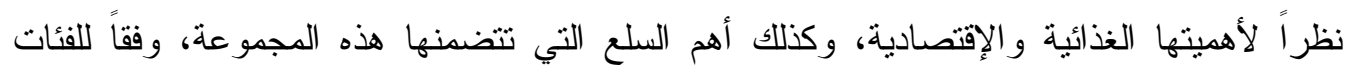

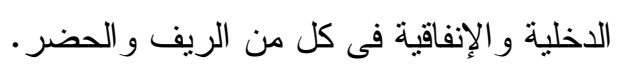

ويهدف البحث إلى إثبات الفرضية الإقتصادية التى تتص عليها النظرية الإقتصادية بتحديد العلاقة الطردية بين الكميات المستهكة من الخضر ومتوسط دخل المستهلك و العلاقة العكسية بين الكمية المستهلكة و أسعار السلع.

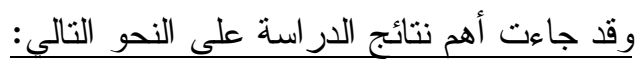

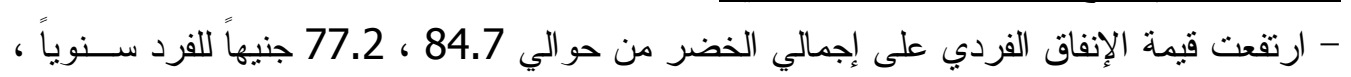

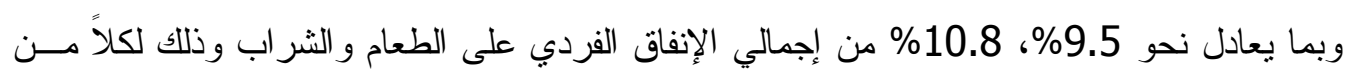

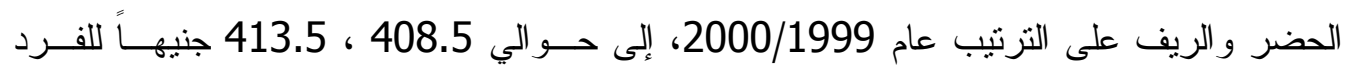

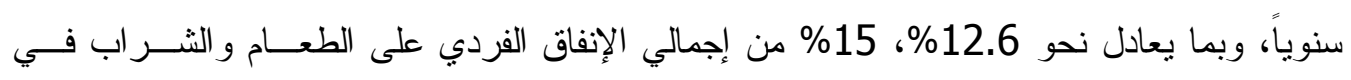

$$
\text { الحضر و الريف على التزنيب في عام } 2015 .
$$

- بزيادة الإنفاق الإستهلاكى الفردى فى الحضر بمقدار الوحدة يزداد الإنفاق على إجمالي الخضر

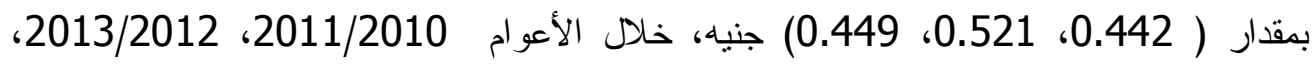
2015 على الترتيب. أما في الريف فبزيادة الإنفاق الإستهلاكى الفردي بمقدار الوحدة يزداد الاعداد

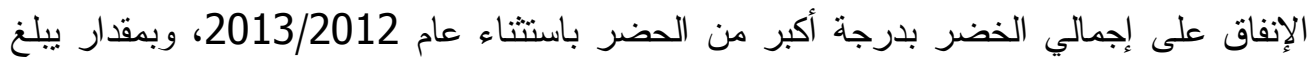

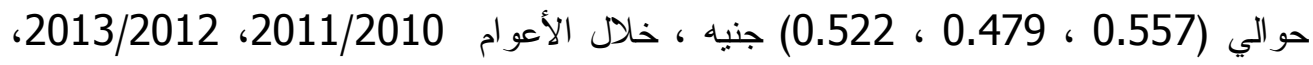
- شهر عامى 2011/2010، 2015 إنخفاضاً فى المرونة الإنفاقية فى الحضر عنها فى الريف، حيث بلغت فى الحضر نحو (0.442 ، 0.449) على الترتيب، بينما بلغت فى الريف حوالى 
(0.557، 0.522) على التوالي، بينما فى عام 2013/2012 إزدادت المرونة الإنفاقية فى (0.521)

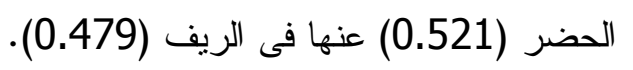

- ارتفاع المرونات الإنفاقية لإجمالي الخضر فى الريف عن الريف الحضر، ويعزى ارتفاع المرونة

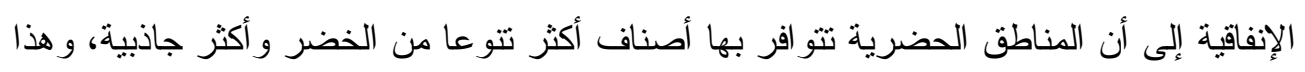

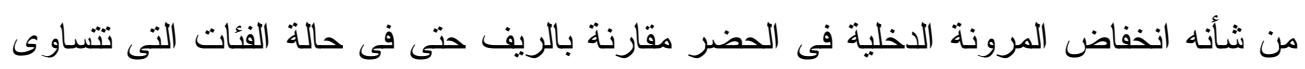

من حيث مستوى الاخل الفردى، فضلا عن أن الأسر الريفية تتسم بثبات العادات الاستهلاكية.

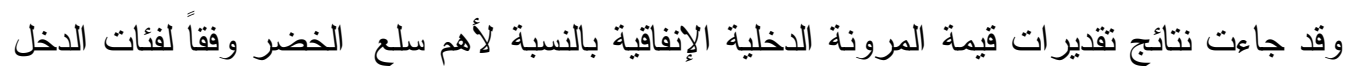

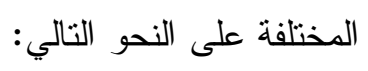

أ-بالنسبة للفئات الاخلية الأكثر انخفاضاً (الطبقة الأكثر فقراً): يعتبر كل من الكرنب والقرنبيط

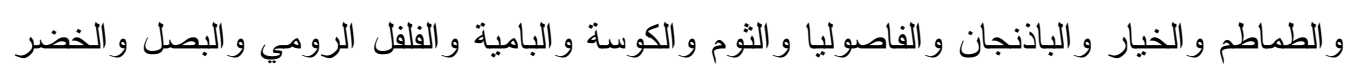

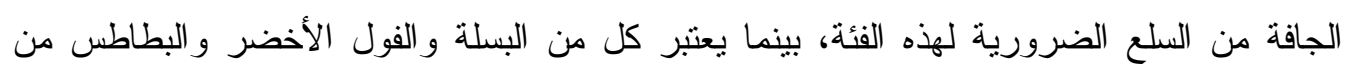
السلع شبه الضرورية لهذه الفئة، أما اللوبيا والجزر و الخضر المجمدة في هذه الفئة فهي من السلع الكمالية.

ب- بالنسبة لذوى الاخول المنخفضة (الطبقة الفقيرة): يعتبر الطلب على كل من الكرنب و القرنبيط

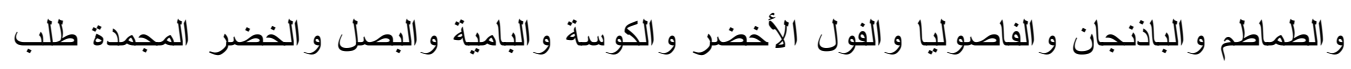

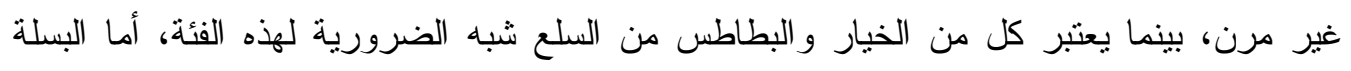
و اللوبيا و الجزر و الخضر المجمدة في هذه الفئة فتعتبر من السلع الكمالية.

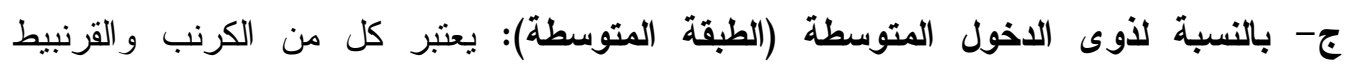

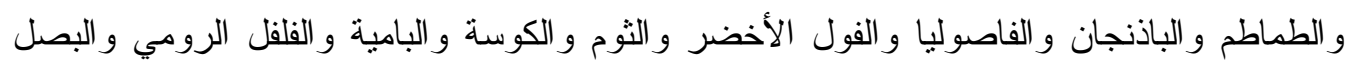

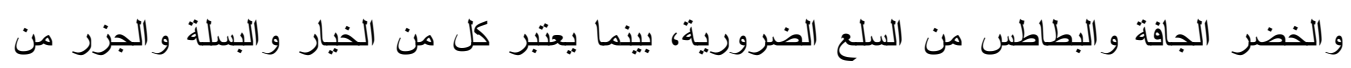
السلع شبه الضرورية لهذه الفئة، أما اللوبيا و الخضر المجمدة في هذه الفئة فتعتبر من السلع الكمالية. د - بالنسبة لذوى الاخول فوق المتوسطة (الطبقة فوق المتوسطة): يعتبر كل من الكرنب و القرنبيط

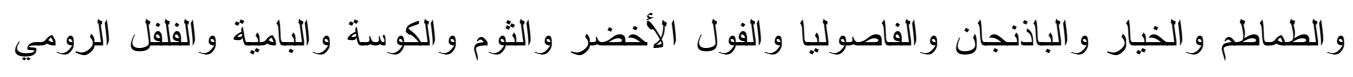

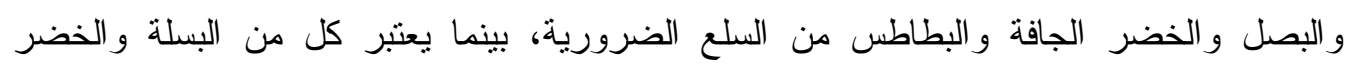

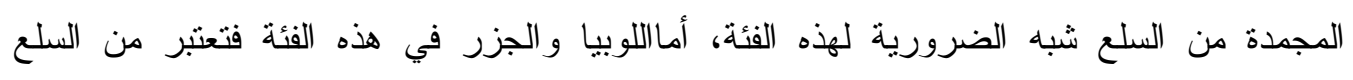
الكمالية.

ه - بالنسبة لذوى الاخول المرتفعة (الطبقة الغنية):

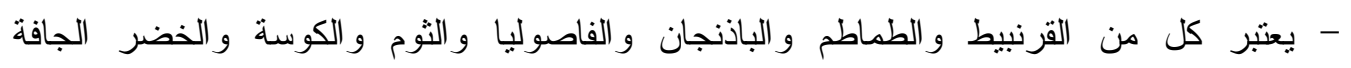

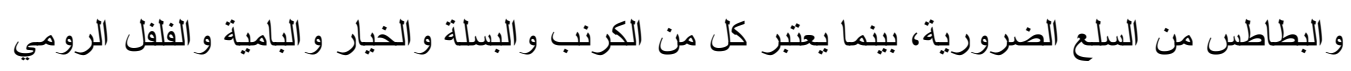

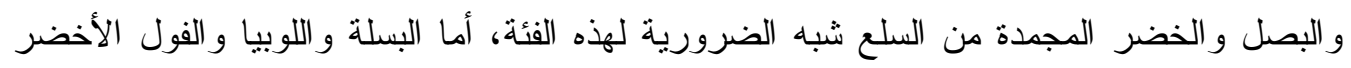
و الجزر في هذه الفئة فتعتبر من السلع الكمالية. 


\section{أما هدى تأثير العو (مل الإجتماعية تتلذص فى التالى:}

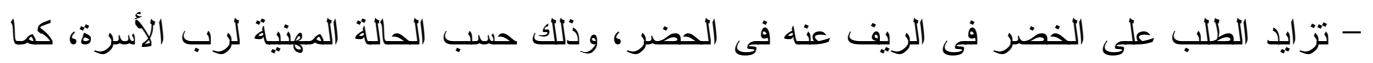

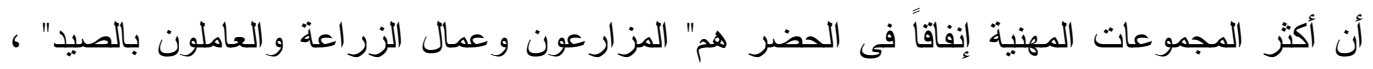

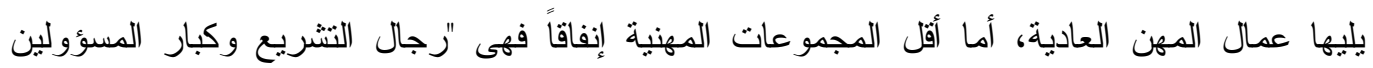

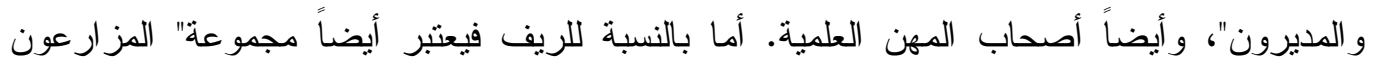

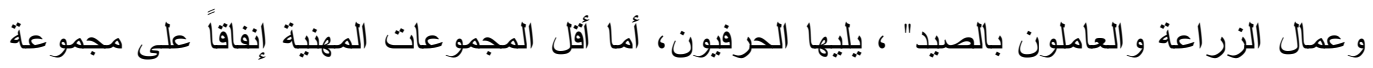

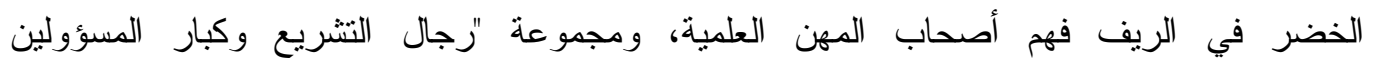

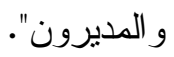

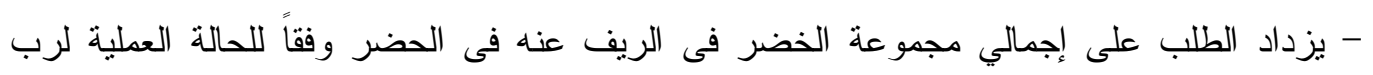

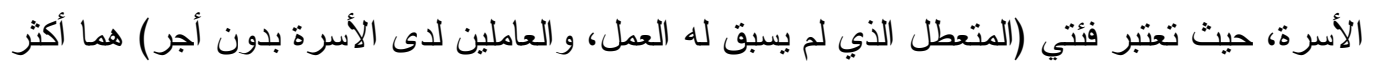

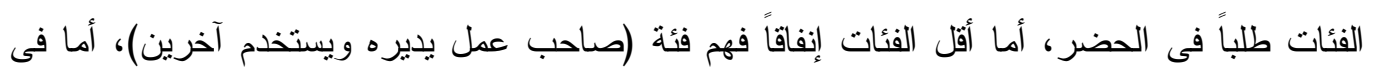

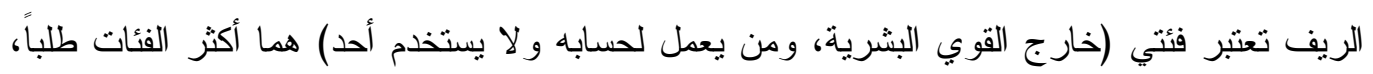

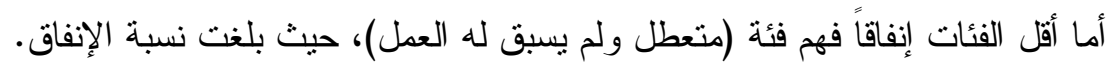

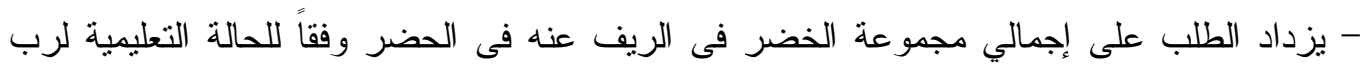

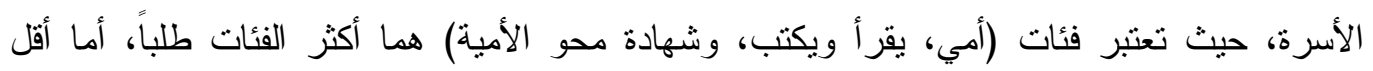

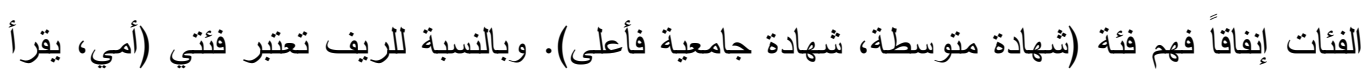

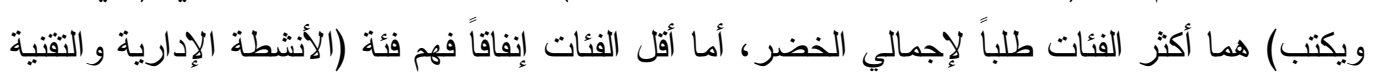

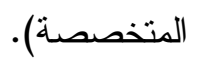

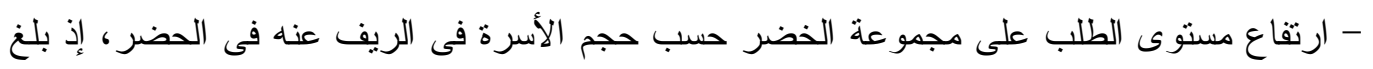

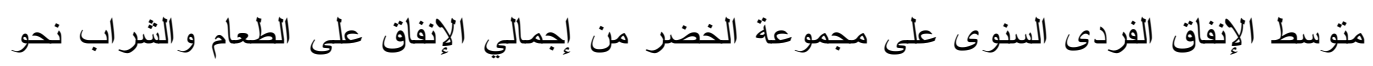

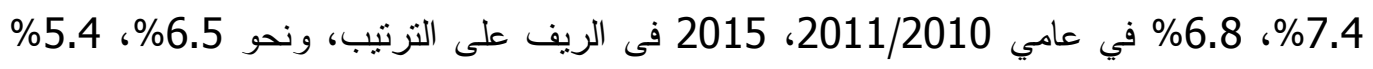
في الحضر خلال نفس العامين على الترنيب.

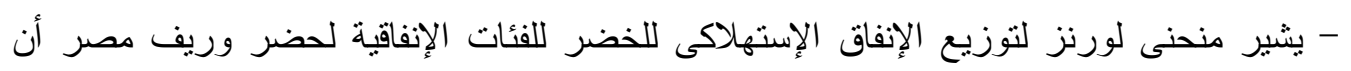

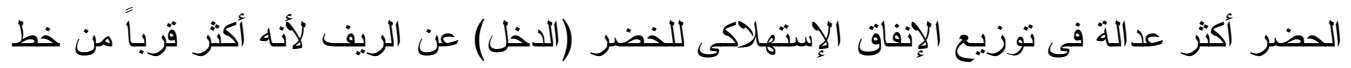

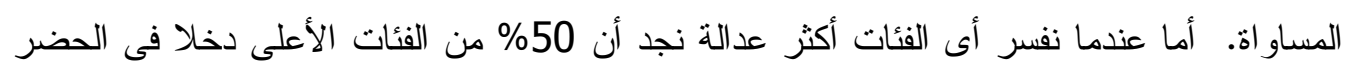

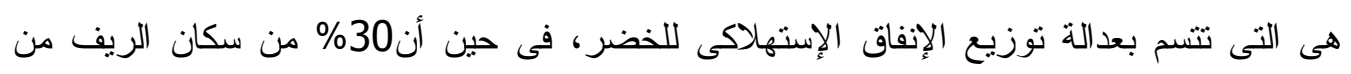

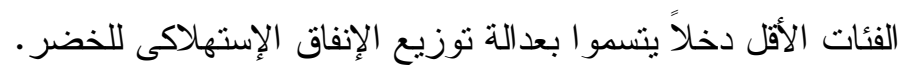




\section{التوصيات}

1. توجيه الدعم للفئات الأكثر فقراً و العمل على عدم رفع الدعم الحكومي بشكل كلي. 2. تحسين المستوى المعيشي للمستهكين مع استكمال الحكومة لعملية الإصلاح الإقتصادي تفادياً

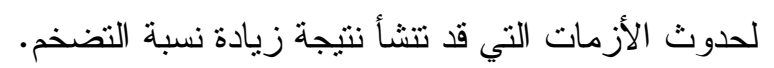

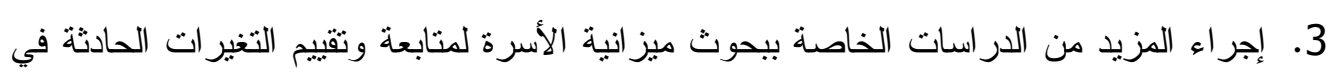

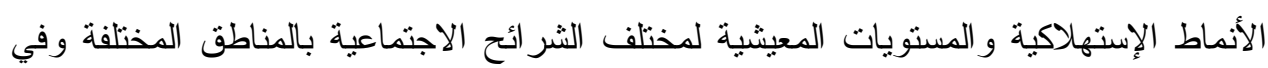
فتر ات زمنية مختلفة. 4. العمل على توفير قاعدة بيانات سنوية للإنفاق الإستهلاكي لعمل مزيد من الدراسات و البحوث

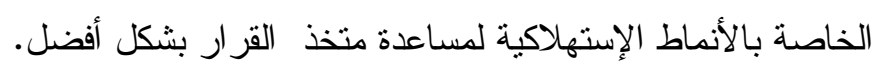

\section{المراجع}

1- أحمد جويلي و آخرون دراسة اقتصادية لبعض تقديرات المرونات الدخلية لمختلف السلع و المجموعات الغذائية في جمهورية مصر العربية"، مجلة الزقازيق للبحوث الزر اعية، 6 (1) ،

2- الجهاز المركزى للتعبئة العامة والإحصاء، بحث الدخل و الإنفاق و الاستهلاك، أعداد متفرقة.

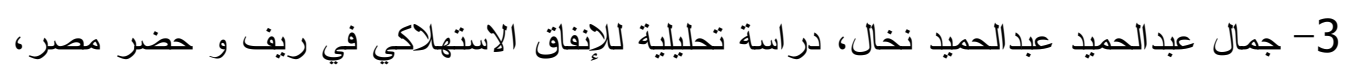
المجلة المصرية للاقتصاد الزر اعي، المجلد (23)، العدد(1)، مارس 2013.

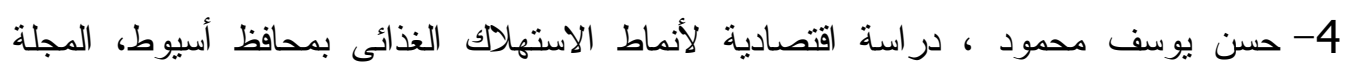

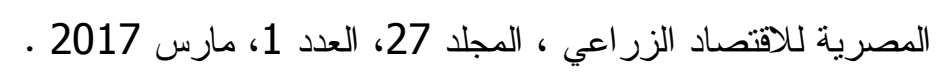
5- رياض السيد عمارة (و آخرون) ، دراسة أفتصادية لدوال الإنفاق على السلع الغذائية فى ليبيا،

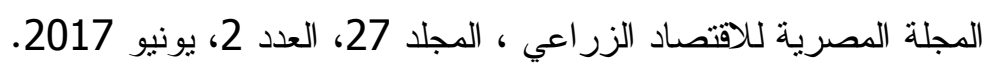

6- عطيات محمد أبو زبد ، محمود عبد التواب عرفة ، دراسة مقارنة للأنماط الاستهلاكية للغذاء

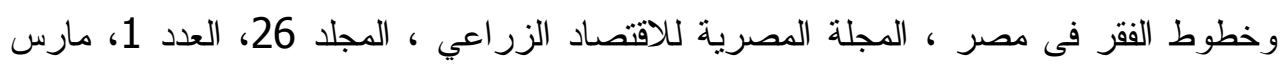
2016

7- محمد مصطفى حسين خليفة، مصطفى عبد ربه محمد القبلاوى (دكاترة)، التغيرات الهيكلية فى الاتى

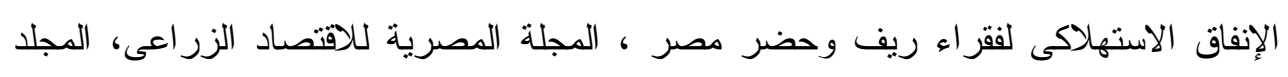
التاسع عثر ، العدد الثالث، سبتمبر 2009.

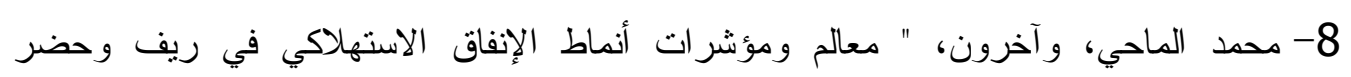

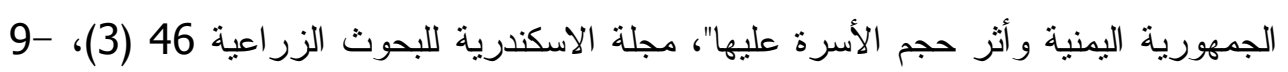
.2001، 21

9- محمد كامل ريحان ، د. السعيد عبد الحميد البسيونى ، مقدمة فى الاقتصاد القياسى ، جامعة عين شمس ، كلية الزر اعة ،2013. 10- مركز البحوث الزراعية، معهد بحوث الإقتصاد الزراعي، قسم بحوث التحليل الإقتصادي

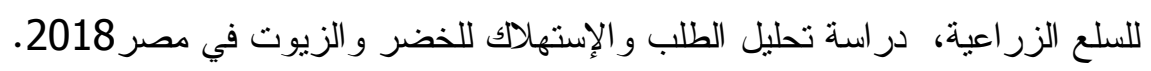


11- هناء شداد محمد ، دراسة مقارنة للإنفاق الإستهلاكى على المجموعات الغذائية الرئيسية فى

ريف وحضر مصر ، المجلة المصرية للاقتصاد الزراعي ، المجلد 24، العدد 3، سبتمبر لإنير

.2014

12- هنادى مصطفى عبد الر اضى ، أزهرية على البشرى ، دراسة أقتصادية مقارنة للإنفاق

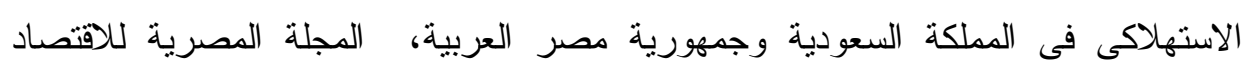

$$
\text { الزر اعي ، المجلد 26، العدد 3، سبتمبر } 2016 \text {. }
$$

13- وزارة الزراعة واستصلاح الأر اضي - قطاع الثئون الاقتصادية- نشرة الميزان الغذائي

$$
\text { لجمهورية مصر العربية، } 2015 .
$$

14- Ecker, Olivier and Qaim Mati. 2008. Income and Price Elasticities of Food Demand and Nutrient Consumption in Malawi, Goettingen, Germang.

15- Mittal Surabhi. 2006. Structural Shift in Demand for Food, Projections for 2020, India. 